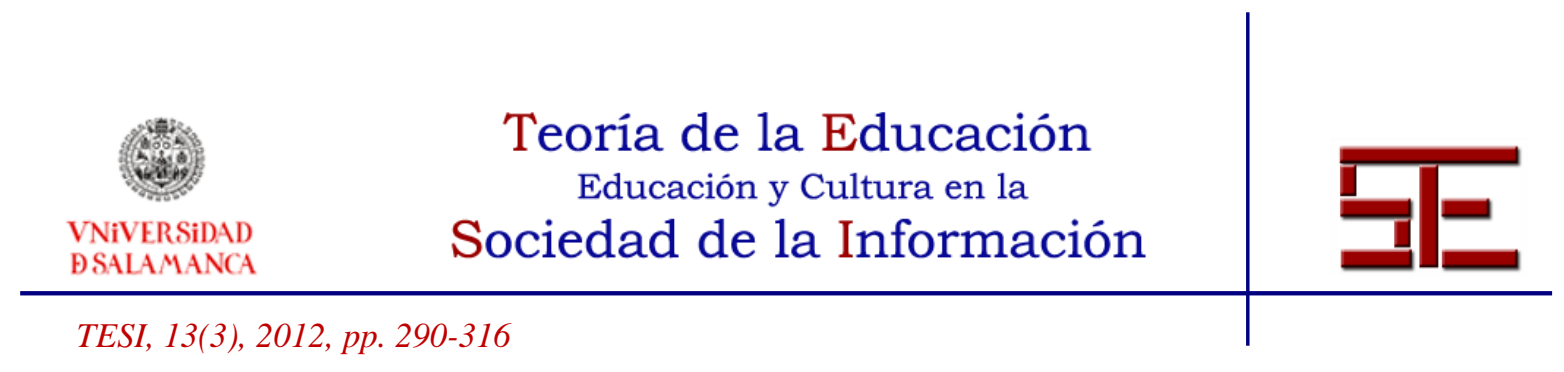

\title{
APORTACIONES DE LOS MAESTROS EN FORMACIÓN A LA CONSTRUCCIÓN DEL PERFIL DEL DOCENTE COMPETENTE DESDE LA REFLEXIÓN EN EL AULA
}

Resumen: Este artículo recoge los resultados de un estudio realizado para conocer cuál es el perfil del docente competente, mediante la identificación y descripción de las cualidades que los estudiantes de Magisterio atribuyen a los buenos profesores. Se basa en la información aportada por un grupo de 73 alumnos/as de segundo curso de la Diplomatura de Magisterio de Educación Física, de la Universidad de Alicante, del curso académico 2009/10, que atendieron la propuesta de escribir sendas cartas a dos profesores que les hubiesen impartido docencia en cualquier etapa de su trayectoria académica: una dirigida al profesor/a que les impactó positivamente y otra a aquel del que no guardaran buen recuerdo. Por cuestión de espacio, se aportan los resultados de la investigación realizada con las primeras, que se ha abordado con una metodología cualitativa (análisis de contenido) y utilizando el programa AQUAD 6 (Huber, 2006). Los resultados facilitan indicios para identificar el perfil del docente competente para formar a los ciudadanos en la sociedad de la información, en base a cinco dimensiones: cualidades personales, aptitud pedagógica, calidad de sus procesos de interacción, tipología de la formación que promueve y repercusión de su actuación sobre el alumnado. Estas características coinciden significativamente con las que se le atribuyen en la literatura científica y en los planes de estudio de los Grados de Maestro.

Palabras clave: maestros en formación; profesionalización docente; competencias docentes; perfiles docentes.

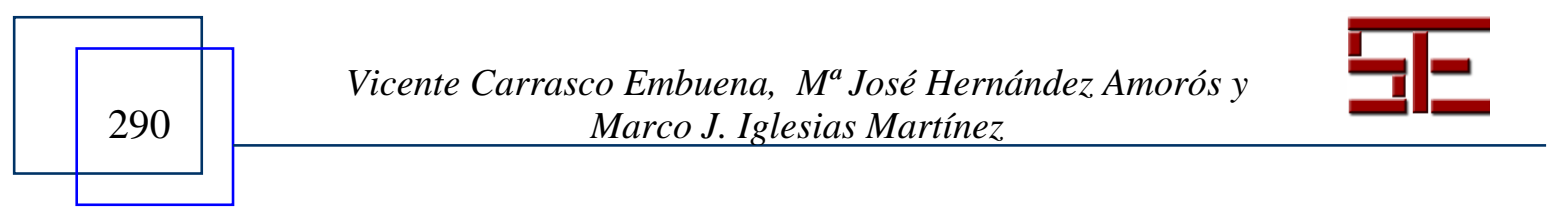




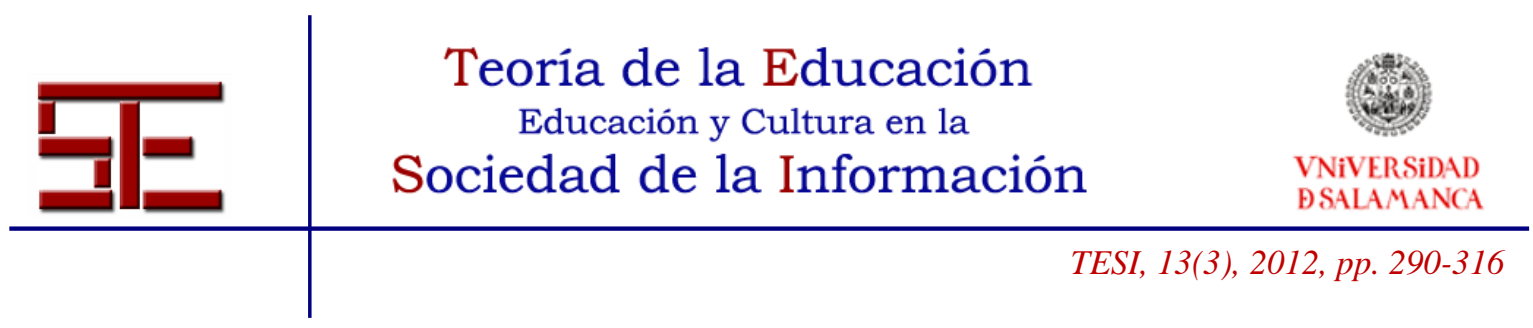

\title{
CONTRIBUTIONS OF TEACHING STUDENTS TO BUILT A COMPETENT TEACHER PROFILE FROM THE REFLEXION IN THE CLASSROOM
}

\begin{abstract}
This paper is the result of a study suggested to recognize what the profile of a good teacher is, by the identification and description of the qualities that students of Teaching Degree attribute them. The study is based on information provided by a group of 73 students of the second course of Teaching in Physical Education Degree, from the University of Alicante, of the academic course 2009/10. The students answered openly the proposal to write two letters to two of their teachers at any stage of their academic career: one was addressed to that teacher who had had a profound impact on them, the other, to that person dedicated to teaching but had gone unnoticed in their lives. We have focused our attention only at the letters that they addressed to good teachers because it has been considered the magnitude of the study. Participants have thrown valuable information that has become the engine of this research, qualitative in nature, with which we have studied a number of categories with AQUAD 6 (Huber, 2006) programme. The results contribute to draft the profile of a teaching professional to educate citizens in the information society, based in five dimensions: personal qualities of teachers, teaching ability, quality of teacher interaction processes, types of training promoted by the teacher and teacher performance impact on students. These dimensions are basically the same in the scientific literature and in the syllabus of Teaching Degree.
\end{abstract}

Keywords: teachers training; professional development; teaching competence; teaching profile.

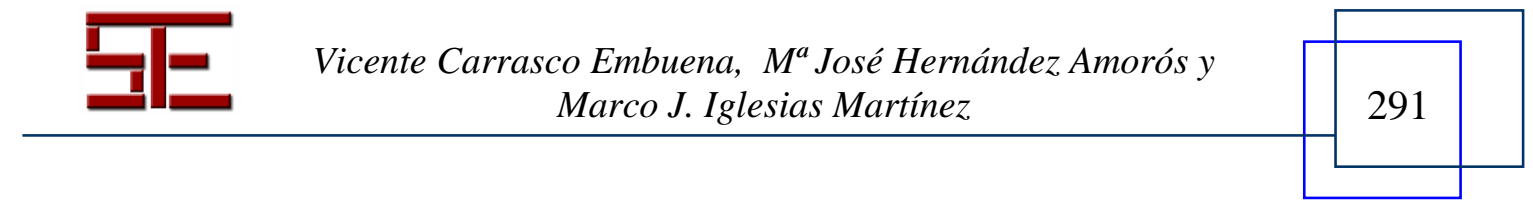




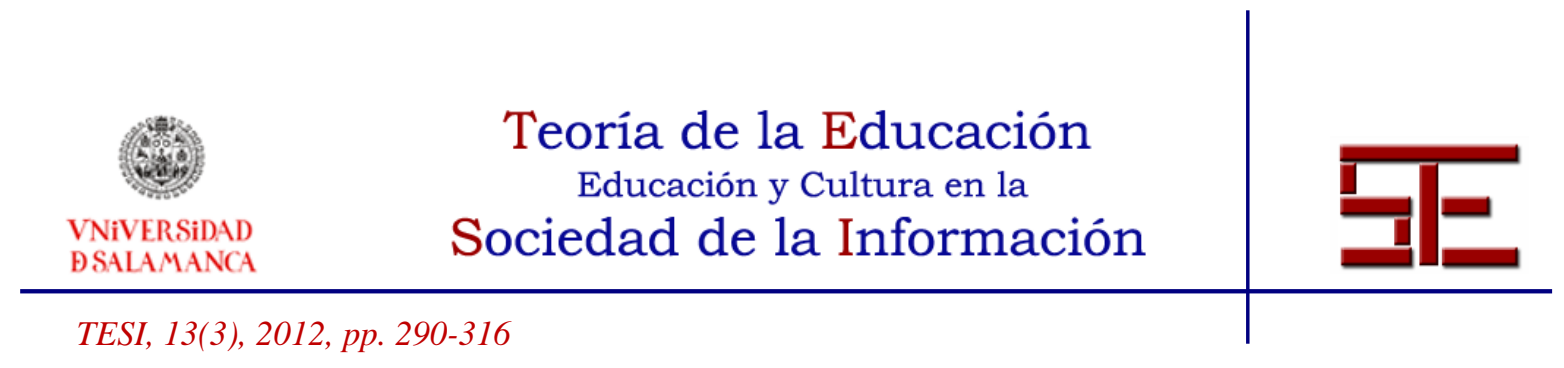

\section{APORTACIONES DE LOS MAESTROS EN FORMACIÓN A LA CONSTRUCCIÓN DEL PERFIL DEL DOCENTE COMPETENTE DESDE LA REFLEXIÓN EN EL AULA}

Fecha de recepción: 28/10/2011; fecha de aceptación: 28/07/2012; fecha de publicación: 30/11/2012

Vicente Carrasco Embuena

vicente.carrasco@ua.es

Universidad de Alicante

Ma José Hernández Amorós

josefa.hernandez@ua.es

Universidad de Alicante

Marcos J. Iglesias Martínez

macos.iglesias@ua.es

Universidad e Alicante

\section{INTRODUCCIÓN}

Históricamente se ha discutido e investigado acerca del perfil del docente ideal, sin que se haya alcanzado un acuerdo pleno, una definición incontrovertible, toda vez que no existe un modelo docente único. La multiplicidad de estilos educativos hace que cada profesor construya su propia identidad, no sin dificultades, debido a las diferentes situaciones y cambios a los que se enfrenta en su ejercicio profesional. Harré (1983) describía el proceso de construcción de la identidad como un trayecto que, partiendo de las manifestaciones sociales y culturales, atraviesa su elaboración individual y reservada, regresando al punto de partida, a través de la expresión personal de esas manifestaciones. El interés por la investigación de la identidad profesional del profesorado es relativamente reciente (Bullough, 1997; Connelly \& Clandinin, 1999; Knowles, 1992; Kompf, Bond, Dworet \& Boak, 1996) y proviene especialmente de los ámbitos social y filosófico. Las diversas aportaciones subrayan su carácter evolutivo, que forma parte del ser y que se desarrolla, a su vez, por las interacciones con el ambiente (Beijaard, Meijer \& Verloop, 2004). Por ello, la identidad profesional se refiere no sólo a las influencias sociales (incluidas las imágenes aceptadas de la sociedad acerca de qué debe saber y ser un maestro), también depende de la capacidad de los profesores para valorar su práctica basándose en su bagaje experiencial (Tickle, 2000).

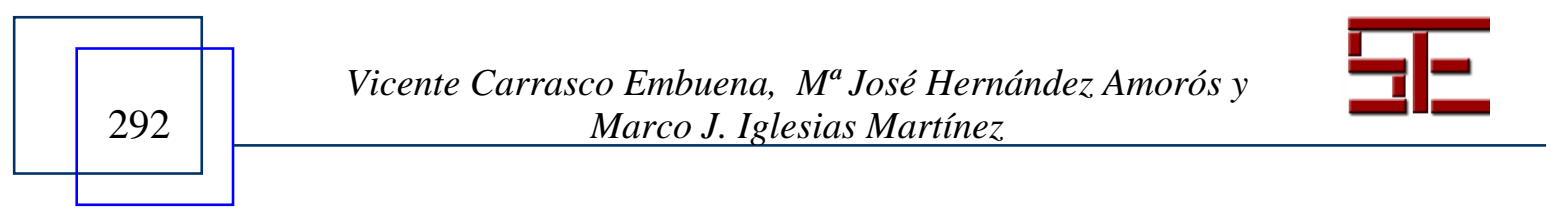




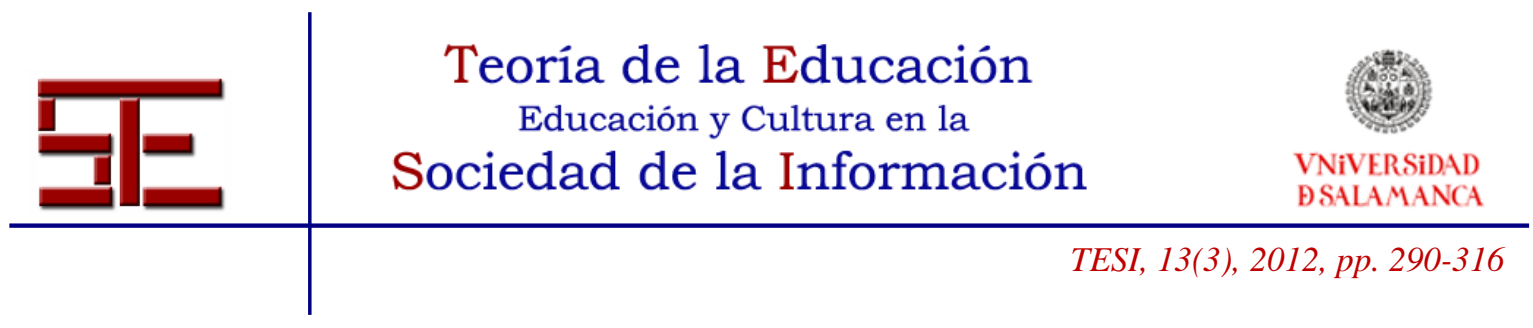

Así pues, la identidad profesional no es un concepto estable ni unitario (Coldron \& Smith, 1999), sino que su homeostasis depende de la imagen profesional que se forja cada profesor y del rol que considera que debe asumir (Volkmann \& Anderson, 1998). En este sentido, lo que nos ha interesado en este caso es exclusivamente conocer el perfil del docente competente. No pretendemos abarcar un concepto mucho más amplio y controvertido como la identidad y la multiplicidad de aspectos que pueden determinarla (Cooper \& Olson, 1996). Por ello, hemos optado por focalizar este trabajo en el análisis de aquellas competencias que configuran el perfil de un docente competente según las percepciones y asunciones de los alumnos/as en formación.

La preocupación por conocer qué hace que un docente sea competente ha generado diversas ideas, opiniones y teorías (Avent, 1931; Barr et al., 1955; Borich, 1986; Reid, 1999). Actualmente, se ha superado la visión tradicional sobre la existencia de un modelo único de profesor ideal (Cruickshank \& Haefele, 2001) y se reconoce la variedad de los modelos docentes de calidad, que ofrecen directrices para reconocer diferentes itinerarios para la profesionalización y diferentes visiones acerca de la educación y de la comprensión del mundo. En este sentido, Trueba (1997) o Day (2006) consideran que debe tenerse en cuenta que la profesionalización docente sigue un curso evolutivo, con diversas etapas, que se asocian a un determinado enfoque teórico pedagógico, que a su vez influye sobre los aspectos curriculares de la práctica diaria.

En la actualidad, disponemos de abundantes trabajos sobre la profesionalización docente, que aportan un inventario de competencias que, simultáneamente, identifican las cualidades que mejor definen la excelencia didáctica. Diversos autores (Bar, 1999; Braslavsky, 1999; Becker, Kennedy \& Hundersmark, 2003; Cano; 2005; Perrenoud, 2004 y Zabalza, 2003) han realizado aportaciones significativas para definir las competencias docentes, tanto las profesionales como aquellas que condicionan la personalidad de los profesores y su capacidad para interactuar y relacionarse con el alumnado y con el contexto educativo. Todos reconocen el carácter mutable de esas competencias y destacan la importancia de su adquisición a través de la formación. En el mismo sentido, Imbernón (2002) sostiene que el desarrollo competencial se logra únicamente si la formación inicial y la permanente se nutren de una práctica docente reflexiva y crítica. Ciertamente, el profesorado alcanza elevadas cotas de profesionalización cuando interactúan recíprocamente los componentes profesionales y la auto-realización personal (Sánchez y Boix, 2008). En realidad, tanto un elemento como otro determinan la excelencia docente y favorecen los procesos de enseñanza y aprendizaje diseñados con objetivos pedagógicos que son compartidos por profesores y estudiantes. En ello insiste Zabalza (2009), cuando asegura que la profesionalización

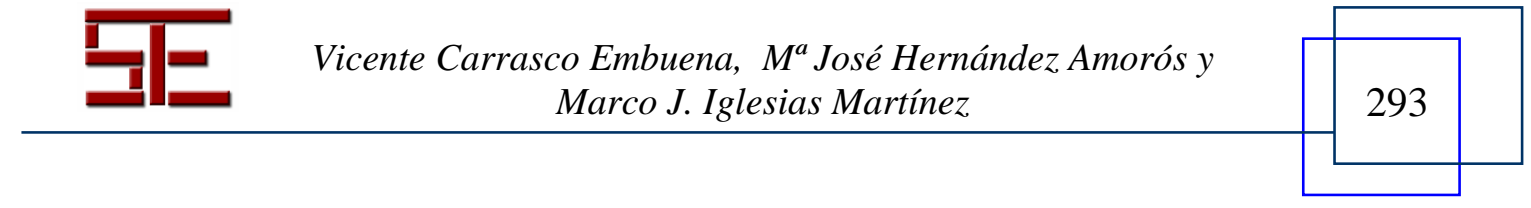




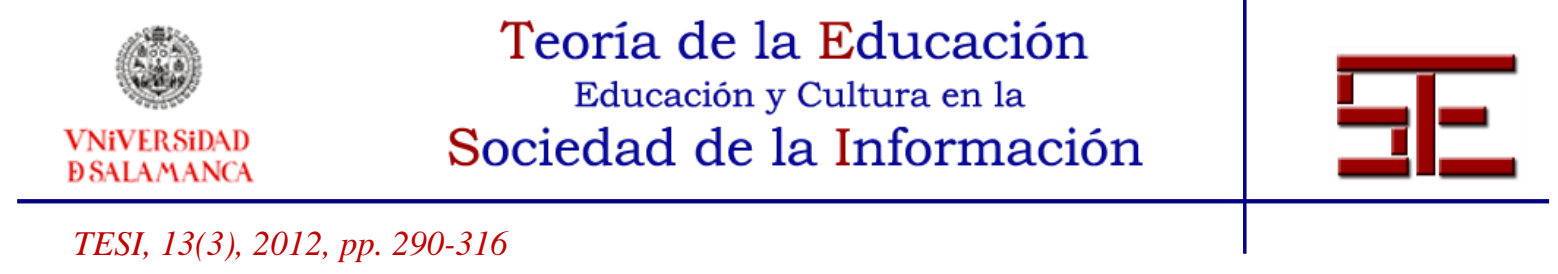

debe ser un compromiso ético que permite desarrollar la formación de los alumnos/as al tiempo que se completa la del propio docente. Por otro lado, García Gómez (1999) subraya que el profesorado que requiere la escuela actual está representado por profesionales conscientes de lo que hacen, con capacidad crítica y argumentos teóricos que apoyan su práctica, y claramente comprometidos con ella. A su vez, Fullan y Hargreaves (1996) mencionan el profesionalismo interactivo y destacan la necesidad de que la profesión se redefina, integrando juicio autorizado, culturas de trabajo en equipo, normas de mejora sostenida, reflexión en y sobre la práctica y, finalmente, una mayor destreza, eficacia y satisfacción en la profesión docente.

En los últimos años, la literatura referida a esta temática ha aportado obras significativas que ofrecen algunas claves para identificar la docencia de calidad. Pasión por enseñar (Day, 2006), El valor de educar (Savater, 1997), Lo que hacen los mejores profesores universitarios (Bain, 2005), Dar clase con la boca cerrada (Finkel, 2008), El profesor (McCourt, 2008), Mal de escuela (Pennac, 2009), Profesores que dejan huella (Castaño, 2009) o Cualidades de los profesores efectivos (Stronge, 2007) son ejemplos de la preocupación por la profesionalización docente, que se erige como tema de relevancia pedagógica. Todos enfatizan la vertiente humana que requiere la profesión, sin menoscabo de la competencia científica de los profesores en las materias que enseñan y del compromiso ético y moral que deben tener con su tarea. Especialmente significativa nos parece la alusión que hace Day (2006) a la pasión como aspecto esencial de la enseñanza de alta calidad.

La formación de los futuros profesores en las facultades es especialmente difícil en épocas de crisis e incertidumbre como la que atraviesa actualmente la sociedad global. A ello, se añade el relativismo existente en la concepción de la escuela y del rol de los docentes. En esta situación de disparidad de percepciones es especialmente necesario delimitar bien los objetivos de la tarea educativa. A tal efecto, consideramos tan pertinente como valiosa la proposición que formula Morin (2000), inclusiva de los siete saberes fundamentales que la escuela debe desarrollar, es decir: ayudar a disipar las cegueras del conocimiento (el error y la ilusión); asentar los principios del conocimiento pertinente; enseñar la condición humana; enseñar la identidad terrenal; enseñar a afrontar las incertidumbres; enseñar la comprensión, y, finalmente, enseñar la ética del género humano.

En los epígrafes que siguen se describe el diseño de la investigación realizada y se aportan los resultados obtenidos agrupados en dos bloques diferenciados, uno que engloba los de carácter demográfico y descriptivo, y otro que incluye los inferenciales.

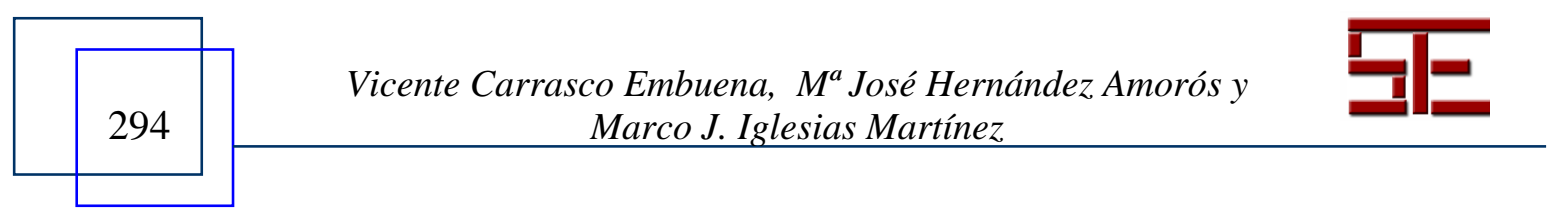




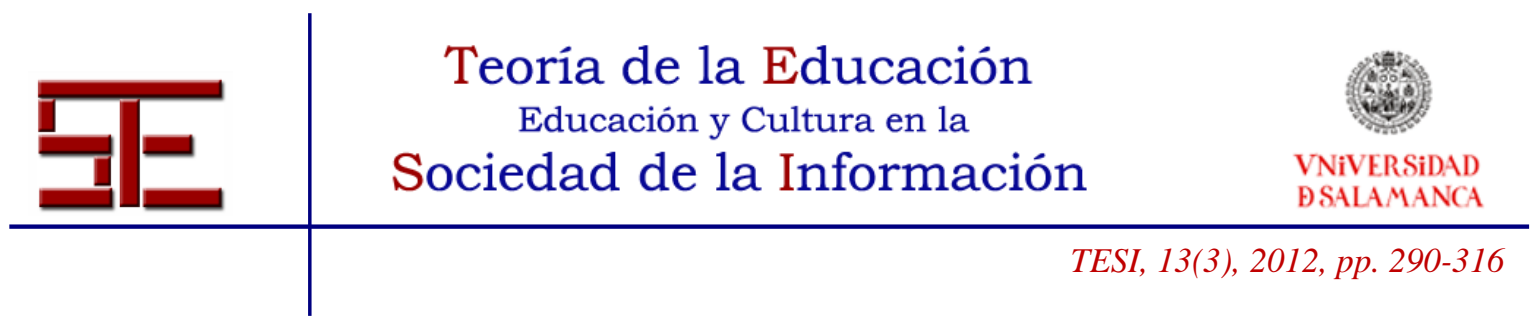

Finalmente, se ofrecen las conclusiones deducidas de los resultados y se señalan algunas implicaciones para enfocar la formación inicial de los maestros y profesores que requiere la sociedad de la información.

\section{DISEÑO DE LA INVESTIGACIÓN}

Para desarrollar la investigación hemos adoptado una perspectiva cualitativa (análisis de contenido), intentando conocer, comprender e interpretar qué piensan los futuros docentes sobre las competencias que han de adquirir los profesores. Como sugiere Silverman (2000), uno de los núcleos destacados de la investigación cualitativa es la atención que presta a los problemas de la práctica cotidiana. Por ello hemos realizado la investigación sobre las producciones de los alumnos en el marco del aula, incardinadas en uno de los trabajos prácticos desarrollados para una de las asignaturas que cursan y, por tanto, en el mismo núcleo en que se materializa su proceso de formación. La propuesta se centraba en la redacción de dos cartas: una dirigida a aquel docente que les había dejado una impronta positiva por su forma de entender y desarrollar la educación y otra, muy distinta, a cualquiera de los otros que, por el contrario, no les habían despertado ningún interés o habían producido en ellos una influencia negativa. Para la elección de los maestros/profesores no se acotaba la etapa educativa en la que hubiesen interactuado con ellos, por lo que se han registrado cartas destinadas a docentes de las distintas etapas del sistema educativo.

Debemos subrayar que la magnitud de los datos y la cantidad de información recopilada sobrepasan las posibilidades de este trabajo, en el que solamente se aborda la investigación de las cartas dirigidas a los profesores/as que dejaron una impronta positiva en los participantes.

\subsection{Objetivos y cuestiones de investigación}

Nuestra investigación pretende conocer, identificar y describir las cualidades que atribuyen los estudiantes de Magisterio a los buenos docentes. Deseábamos conocer si, entre la maraña de asignaturas, créditos, objetivos, competencias, etc., que deben gestionar y adquirir durante su formación inicial, identifican con nitidez los grandes ejes que configuran el perfil del buen profesor/a, porque ello es crucial para que puedan construir el modelo docente que cada uno proyectará en su futuro desempeño profesional. Nos propusimos hacerlo en el ecuador de su formación inicial porque queríamos comprobar, también, si sus percepciones acerca de las cualidades del buen docente se forjaban exclusivamente a través de la formación específica o también estaban influidas por los modelos docentes visualizados y vividos implícitamente a lo

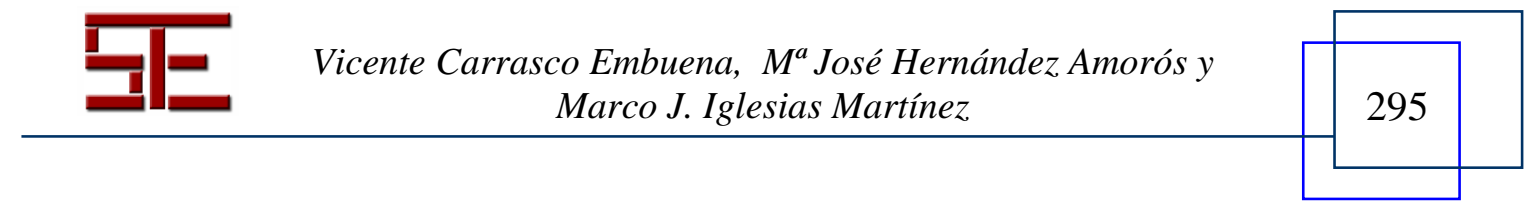




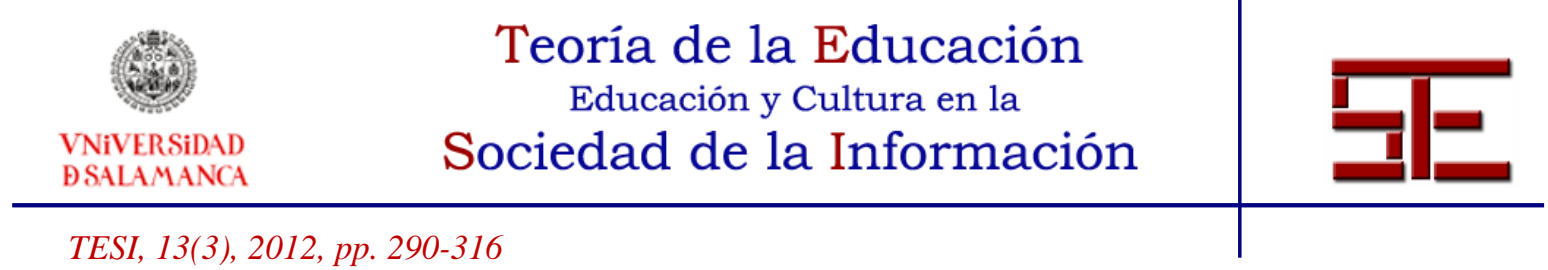

largo de sus trayectorias como estudiantes. Por tanto, el diseño de la investigación está orientado por tres cuestiones:

¿Cuáles son las competencias de los buenos profesores que destacan especialmente los estudiantes en formación?

Sus percepciones sobre el perfil del docente competente, ¿son congruentes con las que aporta la literatura científica?

Las referencias que toman de sus profesores ¿son un elemento significativo para la construcción de su propia profesionalidad?

\subsection{Muestra}

Los estudiantes que participaron en la actividad descrita, que formaba parte del programa de la asignatura Organización del Centro Escolar del segundo curso de la Diplomatura de Maestro de la Especialidad de Educación Física, fueron 73, de un grupo que totalizaba 108 alumnos. Así pues, la participación alcanzó el 67,26\% del grupoclase correspondiente al curso académico 2009/10.

\subsection{Recogida de datos}

En el marco de las actividades que integraban los créditos prácticos de esa asignatura, se les propuso que cumplimentaran un cuestionario de datos sociodemográficos, referidos a ellos mismos y a los profesores a los que dirigían ambas cartas. A continuación, los estudiantes compusieron sus escritos sin ningún tipo de restricciones. Los insertaron en un blog habilitado al efecto, los leyeron autónomamente, analizaron sus contenidos de acuerdo con una pauta que acordaron previamente con el profesor, los debatieron en grupo en clase y seleccionaron los mejores relatos, en base a los siguientes criterios: ajuste al tema propuesto, rigor conceptual, originalidad, riqueza expresiva y presencia de elementos socio-emocionales. Finalmente, los autores de los diez textos elegidos los leyeron en clase, ratificando el grupo general la valoración que habían realizado los grupos de referencia de los autores al seleccionarlos previamente. La riqueza, calidad y significación de sus aportaciones despertó nuestro interés por investigarlas, a cuyo efecto requerimos la autorización a sus autores, que nos la otorgaron unánimemente. El hecho de seleccionar la carta como instrumento para la recogida de datos reside en la idoneidad de esta herramienta para aflorar los aspectos socioemocionales que enriquecen los relatos.

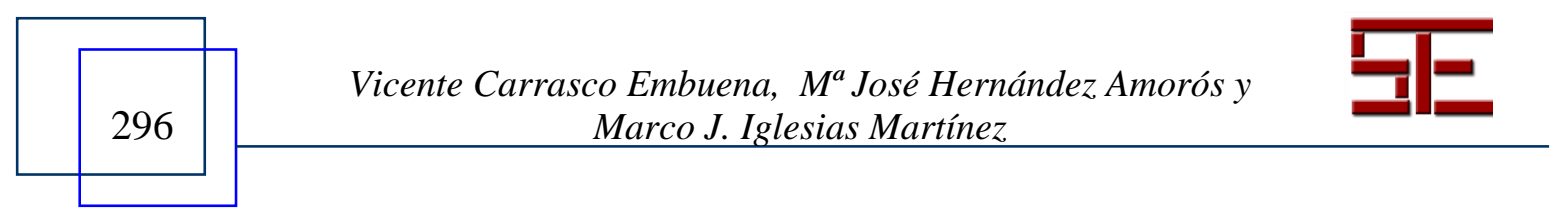




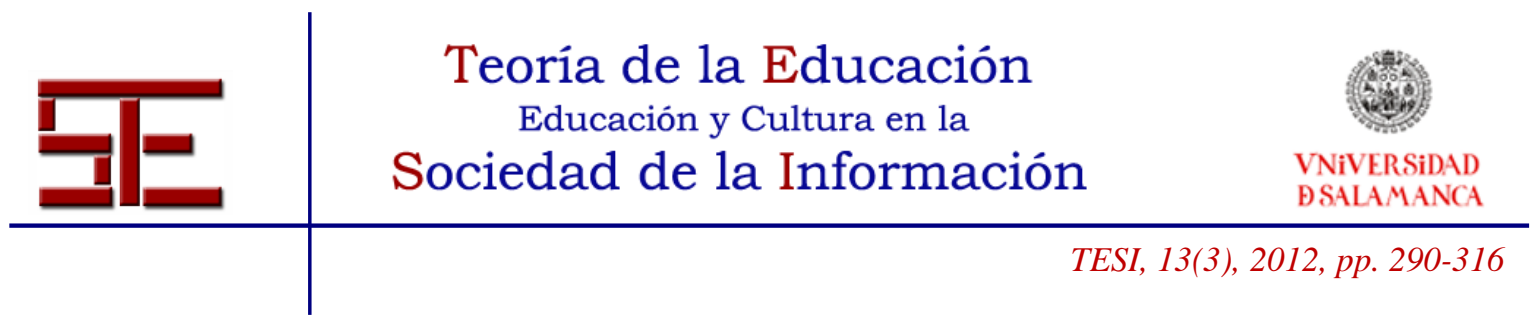

\subsection{Análisis de la información}

Los textos de los participantes se han sometido a un proceso de reducción de evidencias, mediante la selección, simplificación, abstracción y transcripción de los datos que aparecen en ellos que, finalmente, han sido codificados mediante un procedimiento inductivo con el programa de $A Q U A D 6$ (Huber, 2006), emergiendo un conjunto de códigos que se explicitan en el siguiente apartado y que nos han permitido hacer conjeturas y formular conclusiones al relacionarlos entre sí, identificando y contrastando la iteración de determinadas configuraciones típicas en la representación de los datos analizados. Los códigos se han depurado mediante consenso de los investigadores tras lecturas sucesivas. A partir de ellos se ha avanzado hacia estructuras más globales, que denominamos metacódigos o categorías, que engloban importante cantidad de material en unidades de análisis significativas. La validez interna de este análisis se fundamenta en la actuación de cuatro investigadores, que han codificado y puesto en común el sistema de categorías. Su validez externa puede reconocerse en la presentación completa y bien organizada que se aporta de los datos. Singularmente, en el apartado de anexos se incluye una tabla (Anexo 1) en la que se presentan las categorías y los códigos.

\section{RESULTADOS}

A efectos expositivos, los resultados de esta investigación se han organizado en dos apartados diferenciados: uno para los códigos demográfico-descriptivos y otro para los de carácter interpretativo.

\subsection{Definición-interpretación de los códigos demográficos-descriptivos}

La mayoría de los 73 estudiantes participantes tiene 19 años. Por otro lado, accedieron mayoritariamente a los estudios que cursan a través de la Prueba de Acceso a la Universidad (PAU), siendo equiparables los porcentajes de hombres y mujeres.

Con relación a los rasgos característicos de los profesores destinatarios de las cartas, el recuento informa de que se dirigieron a 40 mujeres y a 33 hombres, cuya distribución por edad incluye la Tabla 1.

TABLA 1. Distribución por edad del profesorado

\begin{tabular}{|c|c|}
\hline Edad & $\mathrm{N}^{\mathrm{o}}$ docentes \\
\hline $20-30$ & 7 \\
\hline
\end{tabular}

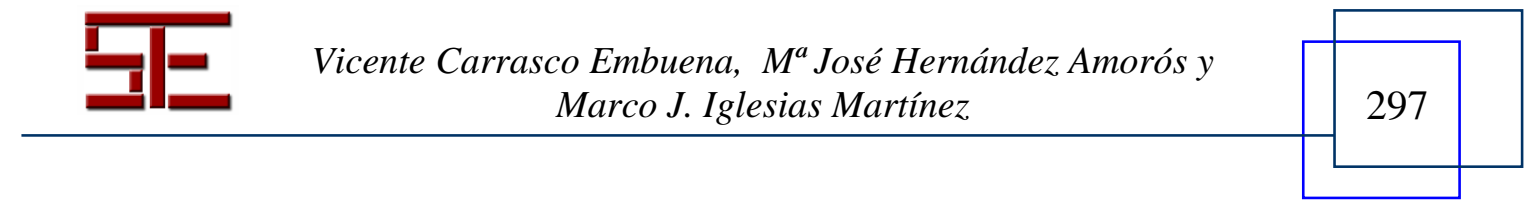




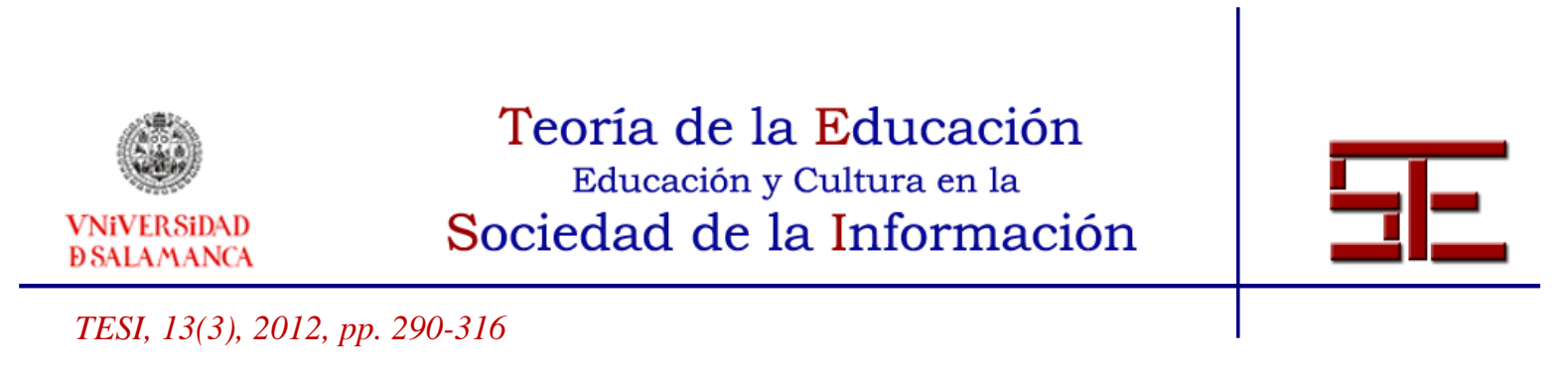

\begin{tabular}{|c|c|}
\hline $30-40$ & 24 \\
\hline $40-50$ & 26 \\
\hline$>50$ & 16 \\
\hline
\end{tabular}

La mayor parte de los docentes destinatarios de las cartas desarrolla su actividad en Educación Primaria (42\%) y en Educación Secundaria (38\%). Por otro lado, la distribución de los profesores/as en función de la materia que imparten es la que contiene la Tabla 2.

TABLA 2. Materias que imparten los profesores

\begin{tabular}{|l|c|}
\hline Asignatura & $\mathrm{N}^{\mathbf{o}}$ docentes \\
\hline Tutor/a & 19 \\
\hline Lengua & \\
Castellana & 8 \\
\hline Matemáticas & 7 \\
\hline Historia & 6 \\
\hline E. Física & 5 \\
\hline
\end{tabular}

*Se incluyen exclusivamente las asignaturas seleccionadas por cinco o más alumnos

Así pues, el perfil característico de los maestros/profesores destinatarios de las cartas es el de un docente de E. Primaria o de E. Secundaria, con edad comprendida entre los 30 y 50 años, indistintamente mujer u hombre, que preferentemente ha sido el tutor del estudiante en alguna fase de su itinerario educativo. En menor medida se trata de un profesor que le ha impartido alguna materia instrumental (Lengua o Matemáticas). En síntesis, es un profesional con notable experiencia, que ha interactuado sostenidamente en el tiempo con los estudiantes (bien porque ha sido su tutor o bien porque les ha impartido alguna materia con gran carga lectiva), siendo irrelevante el sesgo de género en este caso.

\subsection{Definición y análisis de los códigos interpretativos}

La información, que ha emergido de las cartas que los participantes escribieron a sus maestros/as y profesores/as, se ha agrupado en cinco grandes núcleos de contenido o metacódigos, que incluyen los aspectos destacados del docente competente e,

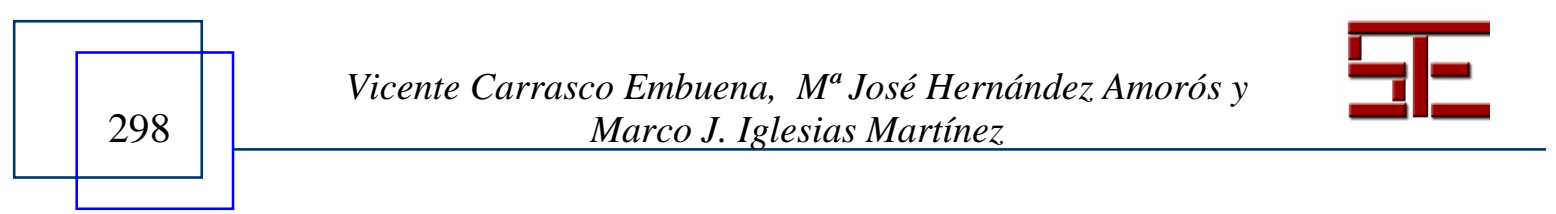




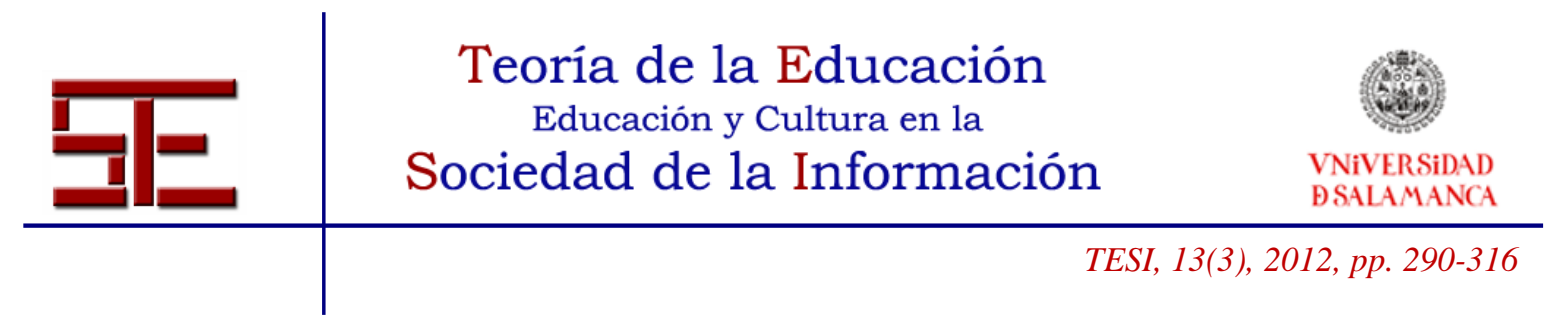

implícitamente, los específicos del incompetente. Los cinco grupos semánticos que aglutinan el esquema de categorías que ha surgido de la codificación son: cualidades personales del maestro/profesor competente, aptitud pedagógica, calidad de los procesos de interacción, tipología de formación promovida por el docente y repercusión de su acción en los estudiantes. Debe subrayarse la concordancia entre estos marcos de referencia en que hemos organizado la información obtenida y las competencias incluidas en los perfiles docentes recogidos en el Libro Blanco del Título de Grado en Magisterio (ANECA, 2005), que sirvieron de referente a la redacción de los correspondientes planes de estudios en las universidades españolas. Esas similitudes entre el repertorio competencial del Libro Blanco (LB) y la síntesis de categorías que ha emergido de las narrativas de los estudiantes se recogen esquemáticamente en el apartado de anexos (Anexo 2).

\subsubsection{Cualidades personales}

Tradicionalmente se ha considerado al maestro como una importante referencia educativa, tanto por su capacidad para transmitir la riqueza cultural compartida por la sociedad como por su integridad personal y moral. Históricamente la figura del profesor ha estado asociada a referencias morales indiscutibles. Su proyección y su capacidad de influencia en las conciencias y en las personalidades de sus alumnos han exigido a los docentes poseer una identidad coherente con un código ético impregnado de valores humanos y sociales. Ello se traduce en un desempeño profesional caracterizado por actitudes y conductas que les cualifican como profesionales pacientes, empáticos, con buena presencia, actitud proactiva, etc. Algunos de los relatos de los participantes en esta investigación ponen de manifiesto la importancia que dan a que maestros y profesores reúnan estos atributos. Así, por ejemplo, realzan la importancia de su buena presencia porque les inspira seguridad y les da confianza:

A mí me sorprendía cómo únicamente con tu presencia demostrabas, al mismo tiempo, respeto, sabiduría, entretenimiento y experiencia (Alu_073).

En el marco de la perspectiva poliédrica que caracteriza a la profesión docente, hemos comprobado que los participantes definen a los maestros/profesores competentes como seres que atesoran un conjunto de cualidades profesionales y personales que atraen su atención. Entre estas últimas subrayan la paciencia y la humildad:

[...] Un carácter muy familiar y dulce, tenía mucha paciencia, tranquilidad y sentido del humor para afrontar toda mala pasada que podíamos hacer en cualquier momento, como niños/as que éramos (Alu_053A).

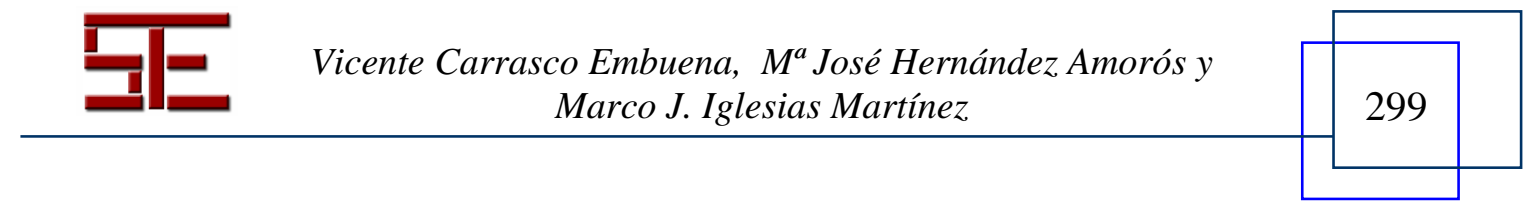




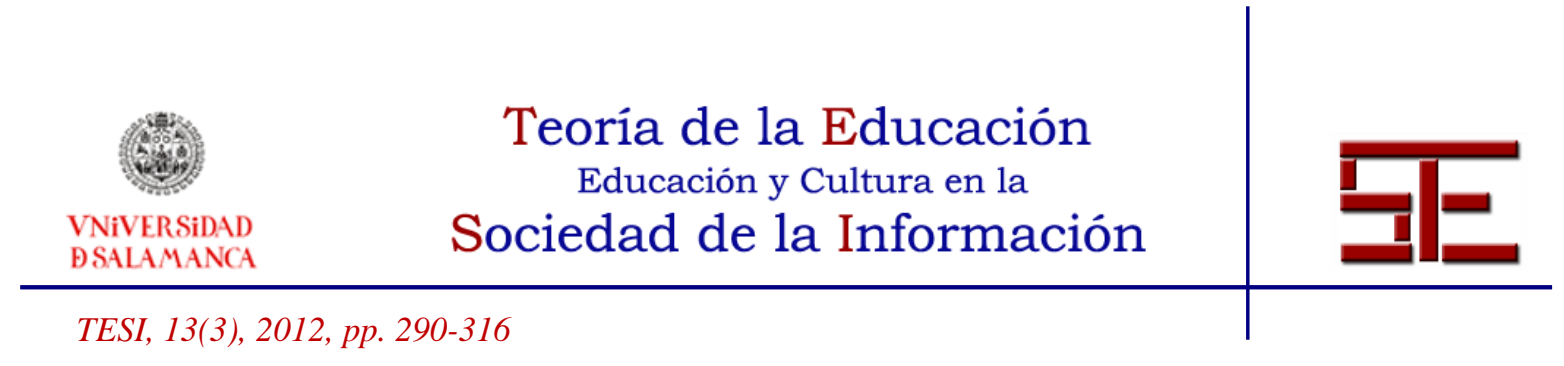

Y lo que más me gusta es que tú misma eres humilde y sabes que te queda mucho por aprender; por ello nunca paras (Alu_058).

Otras cualidades personales cuya importancia destacan los futuros maestros han sido la preocupación que demuestran por los alumnos/as más allá del ámbito escolar y su obstinación por lograr que todo el grupo-clase aprenda, independientemente de las actitudes, aptitudes y demás factores socio-ambientales que condicionan el rendimiento académico de algunos estudiantes. Así lo leemos en sus textos:

\begin{abstract}
En cuanto a la forma de dar la clase era, sin duda, la mejor en su profesión. Explicaba las cosas hasta que todos las entendíamos, si a alguno le costaba más que a otros mostraba más interés en aquellas personas para que no se perdieran en el contenido (Alu_069B).
\end{abstract}

Además, expresan con convencimiento y agradecidos la importancia de que se interesen por ellos, aun después de haber superado la asignatura que les impartían y aunque no les vincule ya una relación cotidiana:

Cada vez que nos veíamos te interesabas y me aconsejabas, como si no hubiese pasado el tiempo (Alu_067).

Otras aportaciones desvelan la importancia que conceden a la personalidad del docente y a los códigos éticos que inspiran sus actuaciones. Ellos los identifican, acentuando la relevancia que tienen los valores y las actitudes positivas para ejercer con éxito la profesión:

Se te veía una buena persona, responsable, que se preocupaba por sus alumnos/as, inteligente, etc (Alu_108).

Usted ha conseguido ser el mejor maestro que he tenido por crear lazos afectivos con todos los alumnos/as de su clase; por fomentar el proceso de enseñanza-aprendizaje; por crear un ambiente motivador que nos ha hecho crecer tanto personalmente como profesionalmente; por estar con nosotros tanto en los momentos fáciles como en los difíciles, por enseñarnos que podemos conseguir todo lo que nos propongamos; por motivarnos con su asignatura; por hacer una educación en valores; por favorecer la cooperación y el compañerismo; y lo más importante, por ser como es (Alu_032B).

\title{
3.2.2. Aptitud pedagógica
}

Aun siendo importantes el armazón moral y las actitudes de los profesores, a juicio de los participantes, su perfil profesional debe incorporar otras capacidades. Según ellos, una de las competencias fundamentales que han de poseer los docentes es el dominio de la materia que imparten y la capacidad de activar diferentes técnicas y estrategias que favorezcan los aprendizajes auténticos del alumnado. En este sentido, podemos leer en sus cartas:

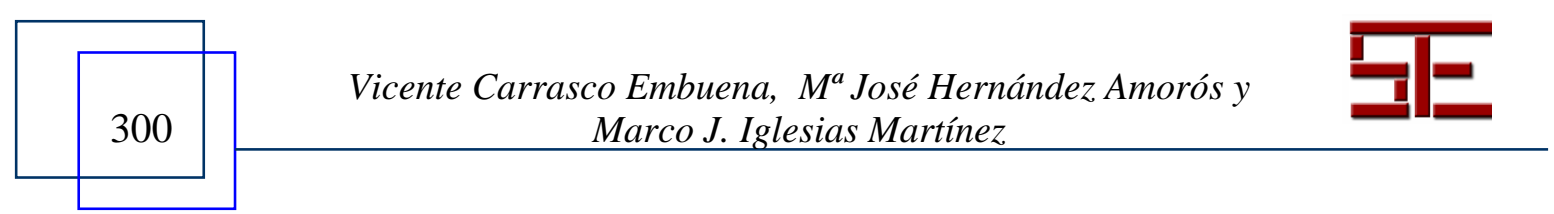




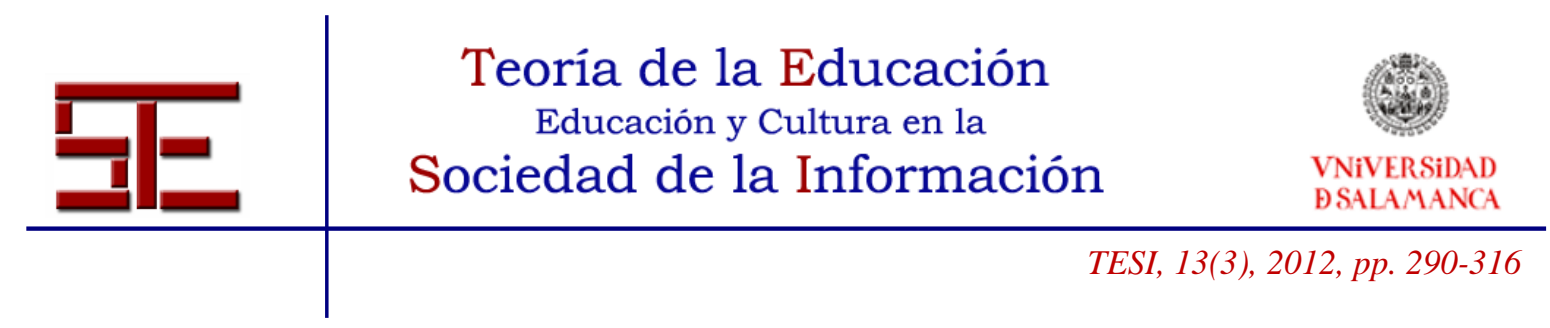

\begin{abstract}
Nosotros, mientras usted nos lo explicaba, nos quedábamos boquiabiertos, no sólo por lo que nos contaba sino por toda la sabiduría que tenía y transmitía. Daba gusto escucharlo (Alu_058A).

[...] Maestro que sabe tantas cosas, que es tan inteligente y tiene tanta cultura. Siempre me acordaré de ti, me has ayudado mucho (Alu_008).
\end{abstract}

Por otro lado, consideran que las metodologías que los docentes utilizan traslucen su carácter y explicitan la concepción que tienen de la educación y los retos que se proponen afrontar. Este es uno de los aspectos que más comentarios ha motivado, de los que transcribimos los siguientes:

Su manera de enseñar siempre ha sido única, proporcionándonos conocimientos al tiempo que confianza (Alu_047).

Tu labor es admirable, cada día era el principio de una aventura compartida con todos mis compañeros/as, esperando que nos sorprendieras con tu metodología (Alu_015).

Además de la importancia que confieren a la metodología, resaltan su capacidad para innovar y para relacionar los aprendizajes teóricos y prácticos y para vincularlos con la realidad, que consideran una herramienta de valor indiscutible:

\begin{abstract}
Cada clase era distinta con usted, no había momento de aburrimiento o de seriedad que fuera necesario, sabía de qué manera tenía que decir las cosas para que hiciéramos caso y nos comportáramos como niños maduros, educados y respetuosos con todo el mundo, pero siempre con ese toque de inocencia propia de un niño de E. Primaria (Alu_045A).

Nunca la Física había sido tan divertida, ni había conseguido despertar tanto interés por mi parte hacia esta asignatura (Alu_029).
\end{abstract}

Otros elementos metodológicos que los estudiantes asocian a la práctica profesional de los buenos profesores es que ofrece la posibilidad efectiva de participar activamente en las clases y de construir el propio conocimiento por medio del debate y la reflexión:

Siempre animándonos y motivándonos con muchas actividades y proyectos cooperativos donde todos colaborábamos y lo pasábamos de maravilla aprendiendo (Alu_054B).

Además, una vez a la semana hacíamos debates donde participábamos todos. Hacía que nosotros, los alumnos, desarrolláramos todas nuestras capacidades y expresáramos nuestras ideas (Alu_069B).

También han mencionado algunos aspectos de la evaluación. De hecho, valoran muy positivamente a los profesores que incorporan la evaluación formativa a sus propuestas de aprendizaje:

La evaluación era continua. Aparte del examen escrito, teníamos que darle redacciones y actividades complementarias para que tuviésemos más notas y no sólo contara el examen

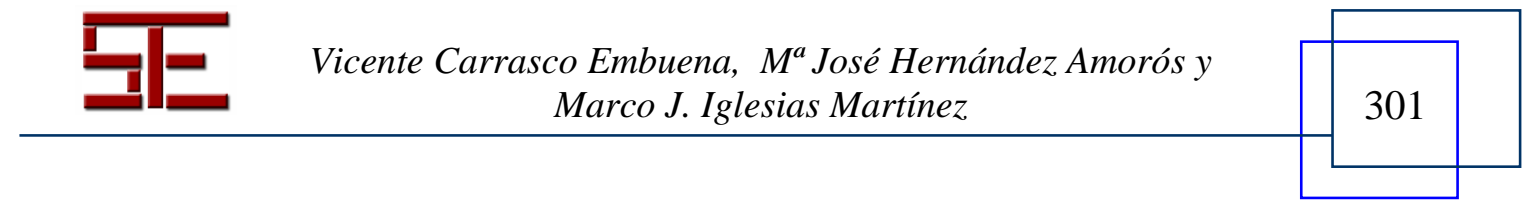




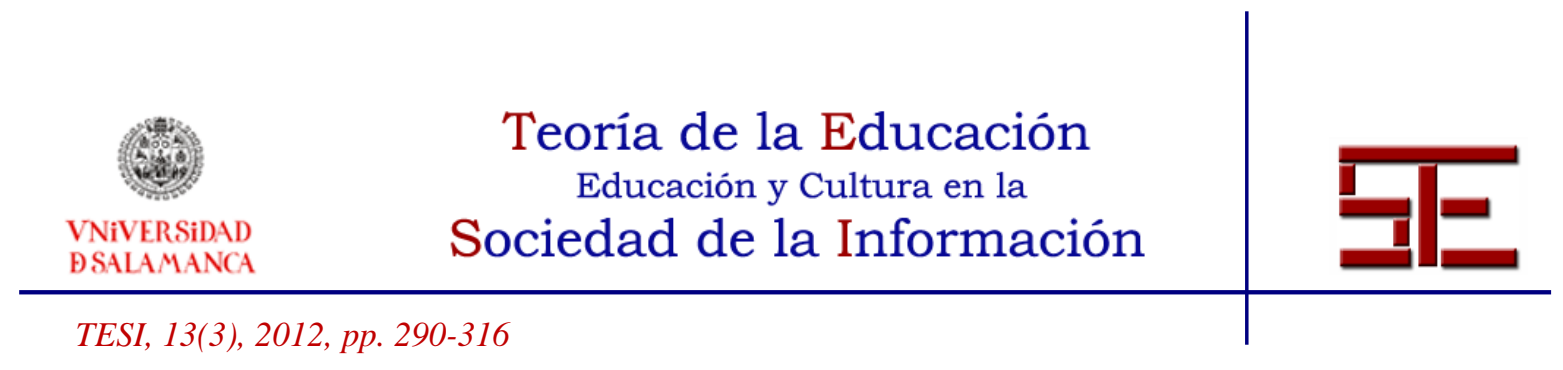

como nota única y excepcional. Por tanto, tenías que trabajar durante todo el curso y no jugártelo todo al final con la prueba escrita (Alu_069B).

Finalmente, han destacado la importancia de que el maestro/profesor sepa combatir la monotonía, consiga innovar para motivar, ofrezca propuestas de aprendizaje activo, etc. Así lo refieren:

Porque nos hiciste proyectos innovadores y progresistas; cada año incluías gran cantidad de innovaciones que nos hacían adquirir infinidad de habilidades y aprendizajes nuevos (Alu_021).

\subsubsection{Calidad de los procesos de interacción}

Los estudiantes participantes consideran actitudes características de los buenos docentes. Su propensión a dispensar un trato cercano a los estudiantes, su empatía y su disposición para incentivar y elogiar el trabajo de sus alumnos/as. Así lo expresan:

Seguidamente, comentar el trato personal que tenía con cualquier alumno. Fuera la duda que fuera, nunca la consideraba fuera de lugar, ni dejaba a ningún alumno en ridículo delante de la clase. Este aspecto le honra muchísimo (Alu_065B).

La disposición para ayudar a los alumnos en cualquier situación y/o circunstancia ha sido otro de los aspectos más reseñados por los participantes:

Nunca había tenido una profesora como tú, siempre atenta a lo que nos ocurría no solamente dentro del aula sino también en aspectos personales fuera del centro, en los que necesitaba un apoyo. Y ahí has estado para ayudarme como una buena amiga (Alu_017).

A su juicio, otro elemento característico de la profesión docente es la capacidad de los profesores para dispensar una atención personalizada a sus alumnos. Así lo expresan:

Nos hacías estar seguros de nosotros mismos, nos hacías sentir especiales a cada uno de los niños que habíamos en tu clase, destacando la virtud de cada uno de nosotros y no nuestros defectos (Alu_068).

Finalmente, la interacción positiva del maestro/profesor con los padres también resulta clave en la concepción que tienen los participantes del buen docente, porque entienden que coadyuva a estrechar lazos entre las dos instituciones más influyentes en la educación de los niños y jóvenes: familia y escuela. Así lo expresan en algunos de sus relatos:

Además, nos hacías comprender que no sólo se ha de llamar a los padres para hablar con ellos cuando se produce un problema (Alu_011).

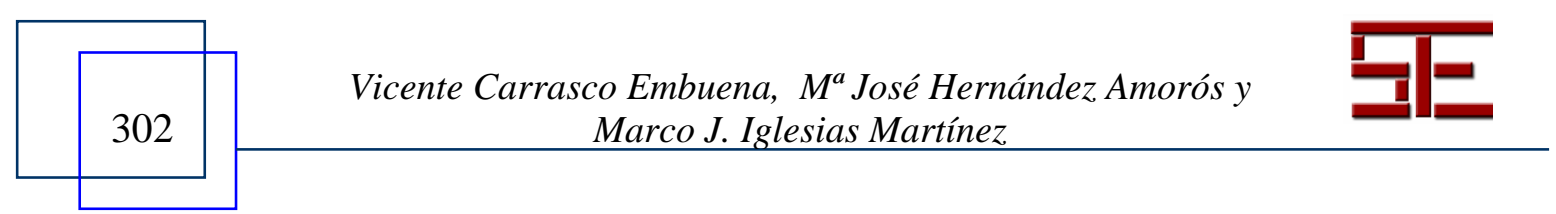




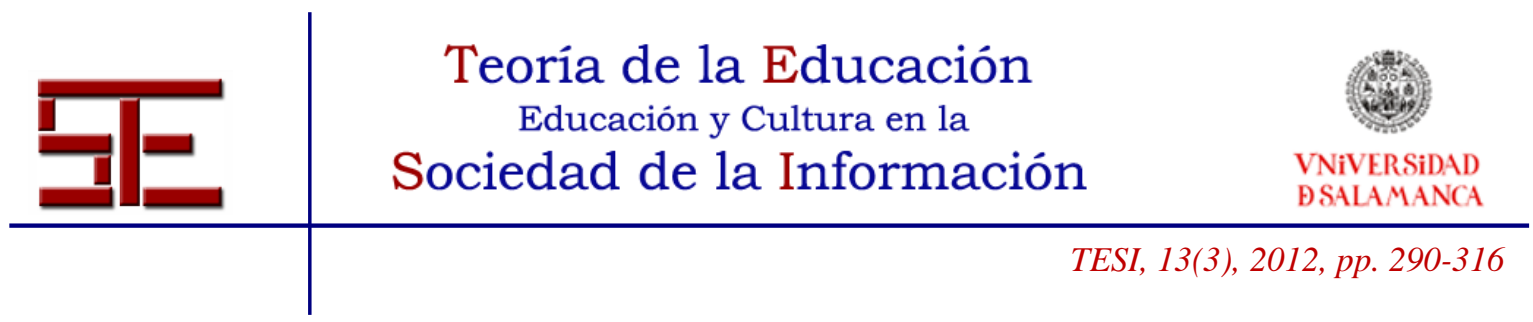

\subsubsection{Tipología de formación promovida por el docente}

En el Informe Delors (1996) se destacaba que la educación tiene entre sus fines principales la formación ético-cívica en una serie de valores que exige la vida ciudadana en un mundo global. También, los participantes en esta investigación han reiterado que educar a los ciudadanos hoy exige contribuir a forjar personalidades críticas, basadas en convicciones axiológicas impregnadas de civismo y capaces de desenvolverse y tomar decisiones exitosas en una sociedad caracterizada por la complejidad. Estos son algunos de sus comentarios:

Por ello, y sin más, te animo a que sigas transmitiendo estos valores que nos han servido de mucho a todos los que hemos tenido la suerte de tenerte como profesora o tutora (Alu_007).

Gracias a ti hemos aprendido a ser mejores personas, y eso ahora...es todo un éxito (Alu_068).

\subsubsection{Repercusión de la acción docente sobre el alumnado}

Por último, subrayan la enorme capacidad de influencia que a veces tienen los docentes sobre sus alumnos/as, hasta el punto de que se convierten en modelos que imitan:

Me gustaría decirle que ha sido mi modelo a seguir, que siempre me he acordado de usted y que me gustaría llegar a ser como usted (Alu_055).

Has sido fundamental en mis estudios porque, si estoy haciendo Magisterio de Educación Física, es porque en un futuro quiero estar haciendo lo mismo que tú y no limitarme nada más a lo que aprenda a lo largo de la carrera, sino continuar formándome para ser un buen maestro y crecer como persona (Alu_050A).

\subsection{Análisis de frecuencias}

Para contrastar la información extraída del contenido de los relatos y el significado que tienen para sus autores, hemos realizado cálculos complementarios sobre las frecuencias relativas de las categorías emergentes de la muestra estudiada y de las correspondientes a las diez mejores cartas, elegidas democráticamente por los estudiantes. Los resultados ofrecen elementos que permiten contrastar el mapa semántico emergente del análisis externo que hemos realizado los investigadores con el que aporta la perspectiva interna de los propios participantes, sintetizada en esa decena de relatos. Como se comprueba en las Figuras 1 y 2, existe una amplia concordancia entre los resultados de ambos análisis.

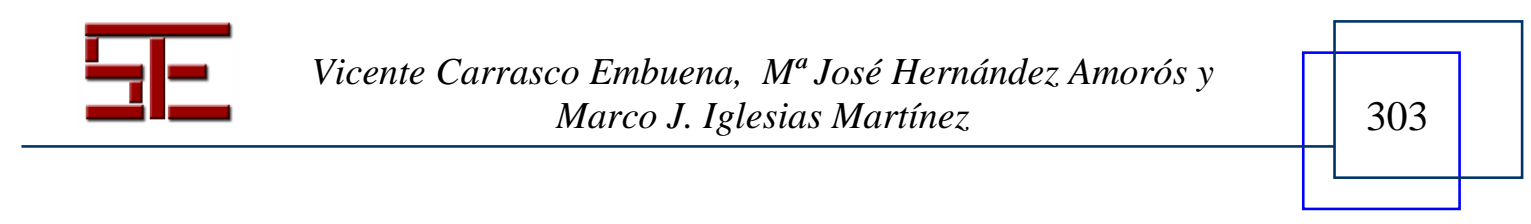




\begin{tabular}{c} 
Teoría de la Educación \\
Educación y Cultura en la \\
$\begin{array}{c}\text { VNiVERSIDAD } \\
\text { BSALAMANCA }\end{array}$ \\
\hline TESI, 13(3), 2012, pp. 290-316
\end{tabular}

\subsubsection{Análisis de frecuencias relativas del total de la muestra}

La Figura 1 permite visualizar las frecuencias relativas de los códigos emergentes en la codificación, es decir, muestra el número de veces que aparece cada uno de ellos con relación a la totalidad de categorías en que se han codificado las narrativas de todos de los participantes.

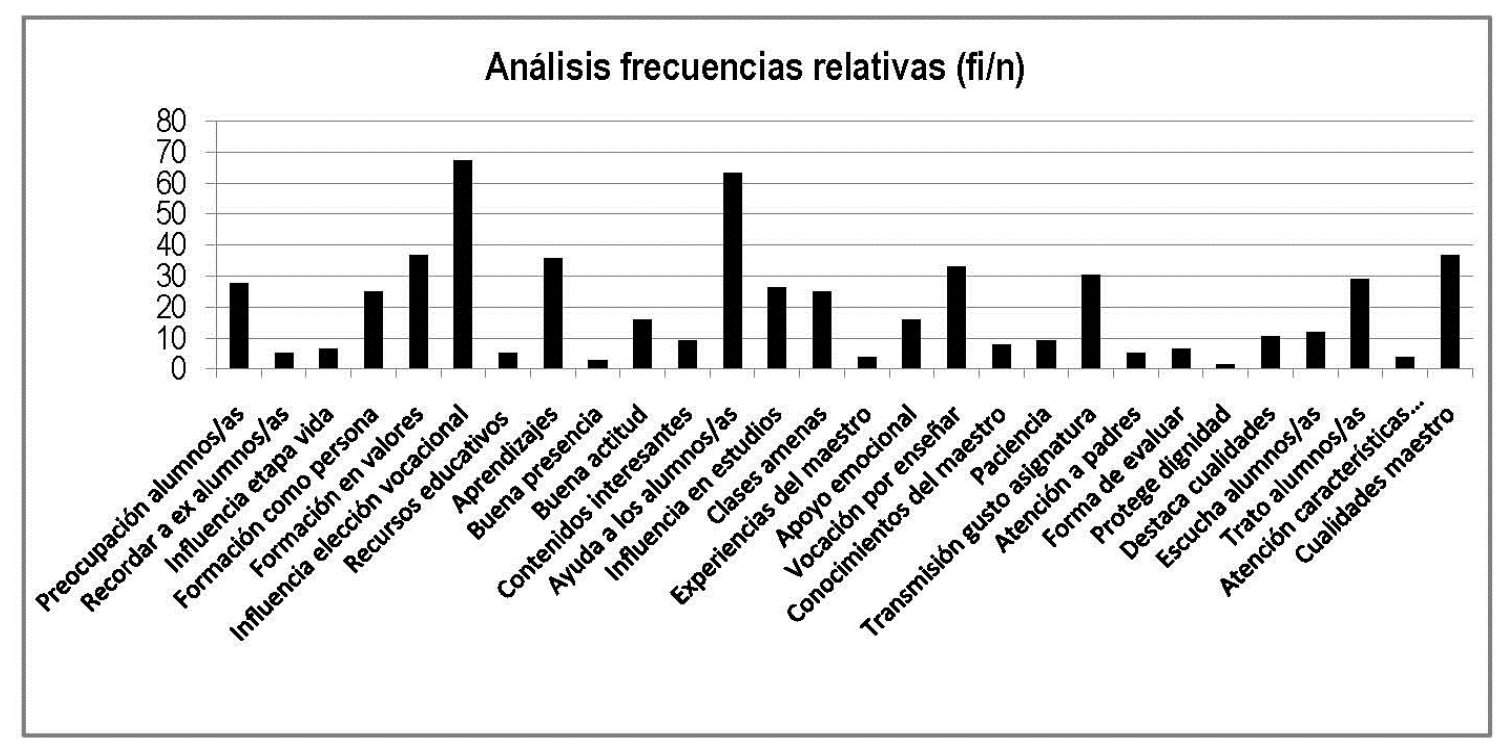

Figura 1. Frecuencias relativas de los códigos emergentes.

Se observa, por tanto, que los códigos más recurrentes han sido: vocación por enseñar $(32,89 \%)$, aprendizajes $(35,53 \%)$, cualidades del maestro $(36,84 \%)$, formación en valores $(36,84 \%)$, ayuda a los alumnos $(63,16 \%)$ e influencia y elección vocacional $(67,11 \%)$.

\subsubsection{Análisis de frecuencias relativas de la selección de las mejores cartas}

En este caso, los códigos que han sido seleccionados de forma reiterativa por los participantes han sido: trato con los alumnos $(40 \%)$ y cualidades maestro (40\%), aprendizajes (50\%), influencia en la elección vocacional (70\%), transmisión y gusto por la asignatura $(70 \%)$ y ayuda a los alumnos/as (80\%).

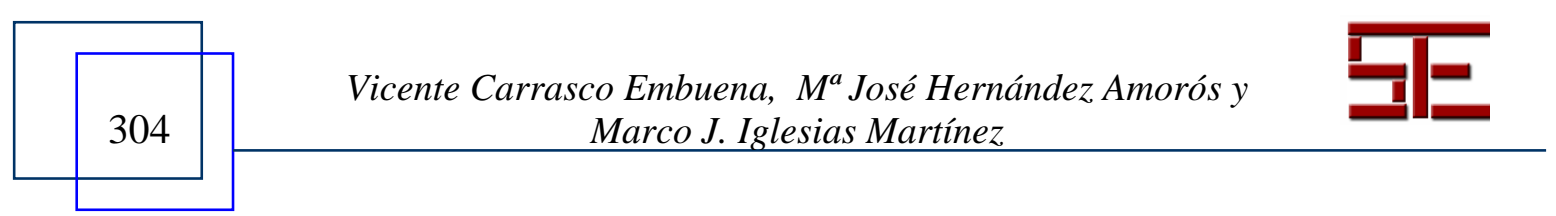



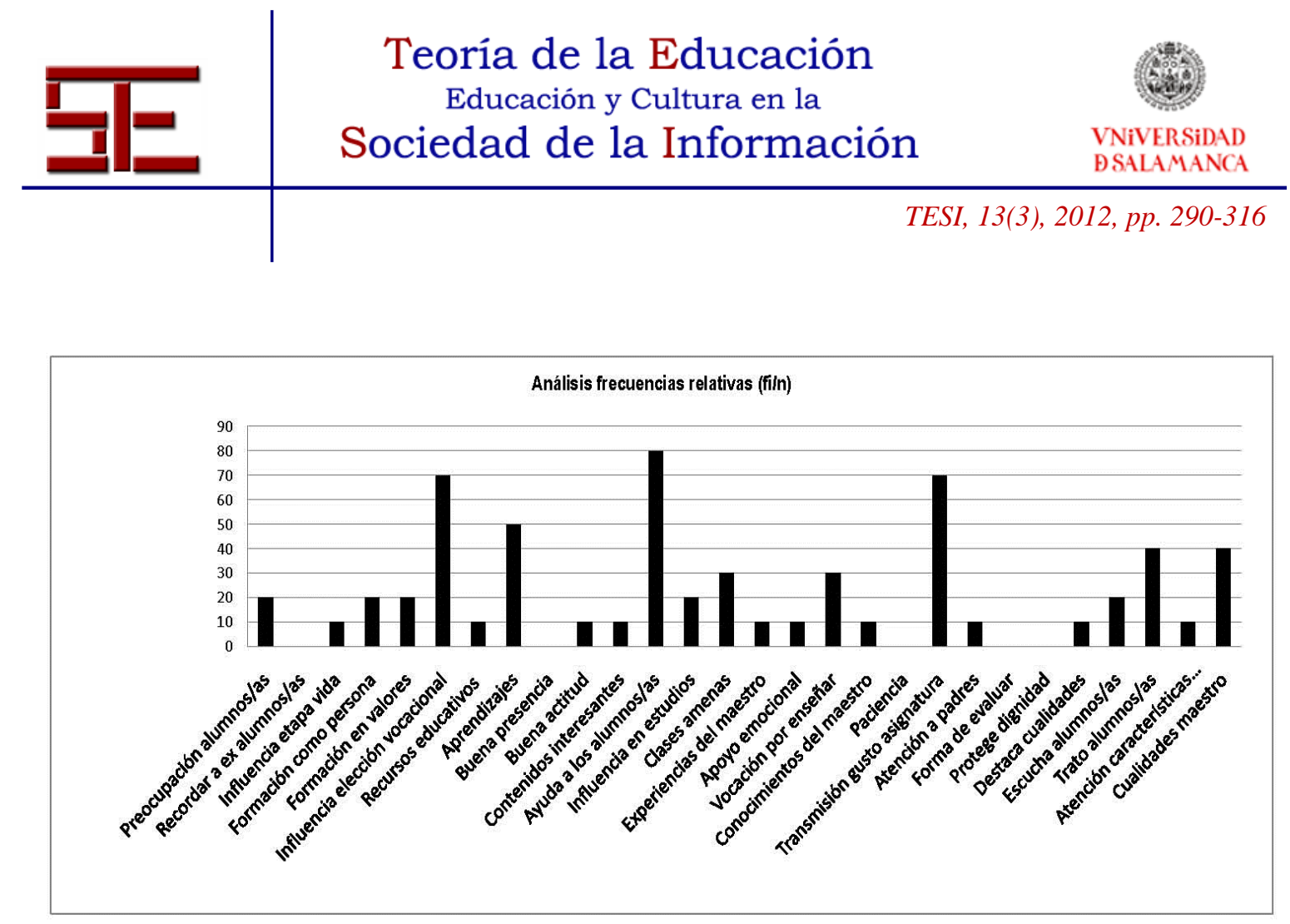

Figura 2. Frecuencias relativas de los códigos hallados en las mejores cartas seleccionadas por el alumnado participante.

Comparando ambas figuras apreciamos gran coincidencia en la especial relevancia que los alumnos otorgan a tres de los metacódigos o grupos de códigos emergentes: cualidades del maestro/a, ayuda alumnos/as e influencia vocacional. Así pues, se comprueba la concurrencia entre las categorías y códigos establecidos como resultado del análisis externo y los que emergen de las ideas de los diez mejores representantes de la población estudiada, seleccionados por consenso de los participantes. Adicionalmente, existe una gran concurrencia de ambos con el desglose de las competencias docentes incluidas en el Libro Blanco del Grado de Maestro, como se comprueba en el Anexo 2.

\subsubsection{Discusión de los resultados}

La primera hipótesis formulada en esta investigación aludía a la valoración que hacen los maestros en formación de sus profesores, no sólo de las técnicas pedagógicas que utilizan para gestionar el aula o mejorar los procesos de enseñanza-aprendizaje, sino también de su entidad como personas. Las aportaciones de los participantes enaltecen inequívocamente el valor humano de la figura del docente, junto a las competencias académicas y profesionales, y manifiestan que se sienten más seguros, confiados y autónomos en la construcción de sus aprendizajes cuando los profesores son tolerantes, abiertos y flexibles.

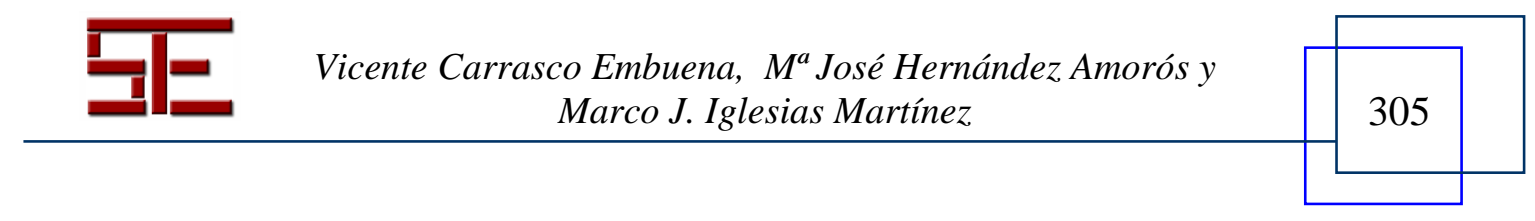




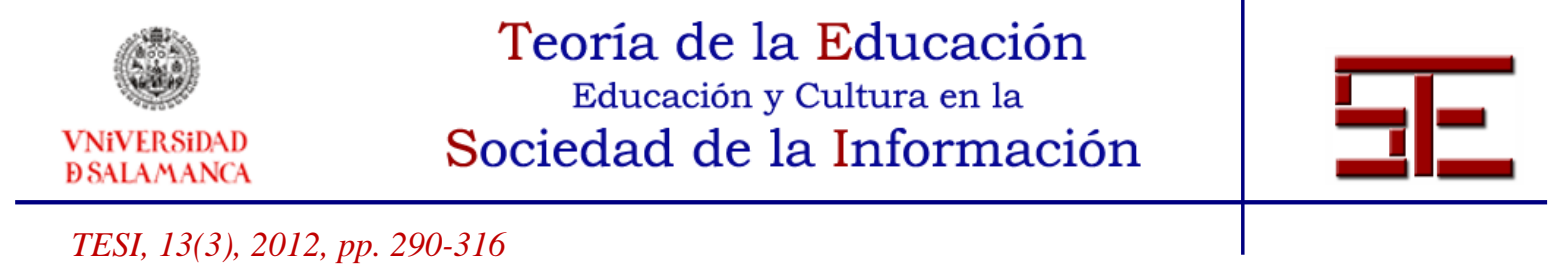

El segundo de los planteamientos tentativos se refería a la hipotética relación entre los resultados hallados en este estudio y en la literatura específica sobre la temática. Ciertamente, se ha constatado un grado de afinidad considerable entre ambas fuentes de información, siendo numerosos los autores señalados en el marco conceptual que identifican un corpus de capacidades que definen al docente competente que es muy similar al que ofrecen las aportaciones de los estudiantes.

Finalmente, la tercera hipótesis apuntaba a la importancia de la influencia de maestros y profesores en la construcción de la profesionalidad de los maestros en formación. A tal efecto, muchos de los participantes aseguran haber elegido los estudios de Magisterio por querer seguir los pasos de aquellos profesionales que tan intensamente les influyeron en un determinado momento de su recorrido académico. Es tal la repercusión de este influjo, que expresan con gran convicción que en su futuro ejercicio profesional aplicarán las técnicas y las estrategias pedagógicas que aquellos emplearon con ellos, así como que desarrollarán las competencias contrastadas en sus maestros y profesores, independientemente de que coincidan o no con las incluidas en el plan de estudios que cursan. Afortunadamente, como se ha referido anteriormente, se ha comprobado que existe una vinculación estrecha entre ambos conjuntos competenciales, tanto a nivel transversal como específico.

\section{Conclusiones e implicaciones}

Las cualidades personales son un aspecto fundamental para definir el polisémico término "maestro" porque cada vez con mayor frecuencia se subraya la importancia de ponderar el conglomerado actitud-aptitud (Stronge, 2007). Es indiscutible que la aptitud, la capacidad pedagógica, es imprescindible para el desempeño profesional, pero no lo es menos que el sentido pleno de los términos "maestro" o "profesor" engloba otras capacidades que trascienden las competencias profesionales stricto sensu. El profesor que influye verdaderamente en su alumnado es un docente con amplias competencias académicas y profesionales, pero también con marcados atributos personales. De ahí que la esencia de su condición resida en su pasión por la enseñanza y en su actitud inequívoca hacia la transformación y la mejora de su práctica, desde la responsabilidad y el compromiso. Los estudiantes participantes en esta investigación han manifestado de forma rotunda que el profesor que consiguió dejar en ellos una huella profunda lo hizo tanto por su capacidad para motivar su aprendizaje mediante técnicas adecuadas como por su actitud, su implicación y su dedicación a impulsar y favorecer su desarrollo académico y personal. Por ello han subrayado algunas de sus

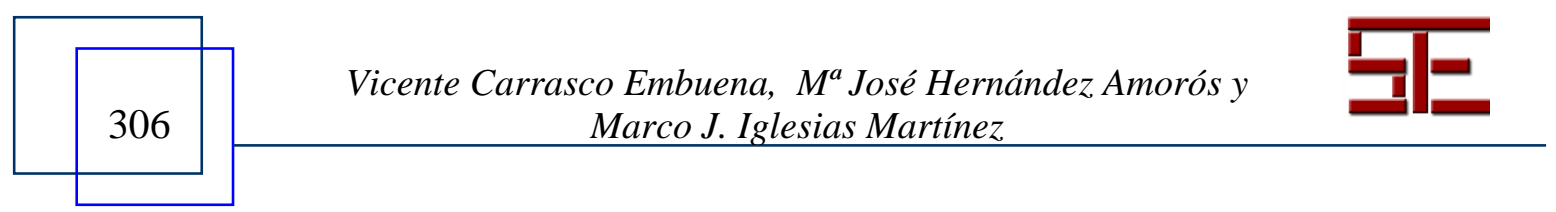




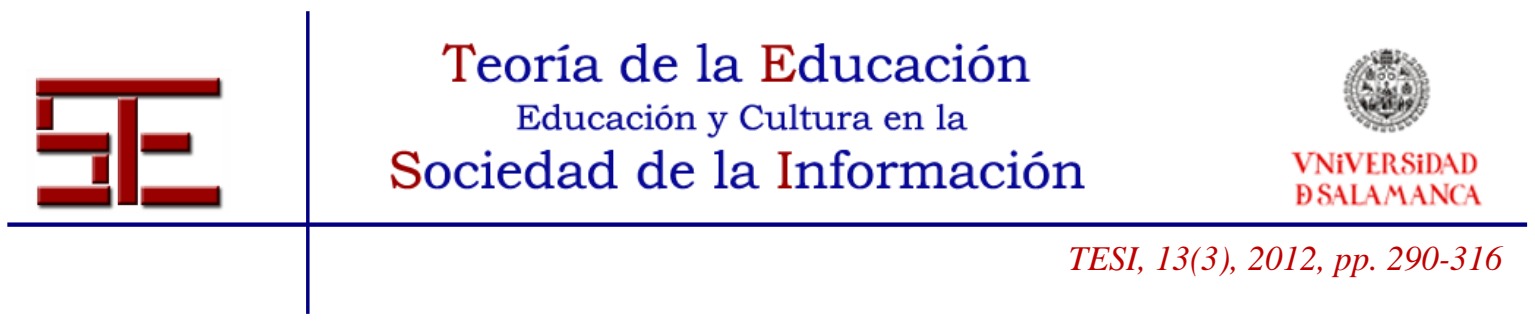

principales cualidades, como la buena presencia, la disposición a la ayuda, la actitud positiva y motivadora, la humildad y la calidad humana, entre otras, como anteriormente incluyen los trabajos de Noddings (2005) y Peart y Campbell (1999).

Por otro lado, a juicio de los estudiantes, la simbiosis entre los aspectos metodológicos y actitudinales condicionan la actividad de los maestros y profesores, generando diferencias apreciables en la efectividad de su práctica profesional. En este sentido, sus voces expresan que piensan que las herramientas docentes activan y optimizan los procesos de enseñanza y aprendizaje si incorporan los avances tecnológicos y se vinculan a los modernos enfoques pedagógicos, que crean oportunidades para diseñar los currículos en entornos innovadores de apoyo a la actividad docente, como también han descrito Coto y Dirckinck-Holmfeld (2007).

Otro aspecto que ha emergido en esta investigación se refiere a la calidad de la interacción que desarrollan los docentes, no sólo con el alumnado (aspecto fundamental, por otra parte), sino también con sus familias e incluso con la comunidad social en la que se inserta el centro educativo. Entre otros autores, Epstein (2001) destacó que el trabajo conjunto de familia, escuela y comunidad estrecha las distancias y configura una plataforma horizontal que repercute positivamente en el funcionamiento de los centros y, por ende, en el rendimiento y en el desarrollo de los estudiantes. El trato familiar, la atención individualizada a los alumnos/as, la capacidad del maestro para realzar las virtudes y obviar los defectos le confieren una aureola de autoridad que revierte en un trato respetuoso hacia su persona, basado en la confianza y en el afecto. También en este caso, las competencias que atribuyen los estudiantes de Magisterio a los buenos docentes incluyen su capacidad de interacción y conexión con el alumnado y con el contexto educativo, que debe ser más intensa de lo habitual, como han reseñado recientemente Cuadrado y Fernández (2008).

También hemos constatado que la vocación por la enseñanza que tienen la mayoría de los participantes en la investigación arraiga en una intensa vivencia de un determinado modelo docente que experimentaron como estudiantes. En este sentido, la repercusión de sus maestros en ellos parece determinante, hasta el punto de que nos atrevemos a pronosticar que muy probablemente ejercerán su profesión influenciados por el legado pedagógico y humano que les transfirieron, intencional o involuntariamente.

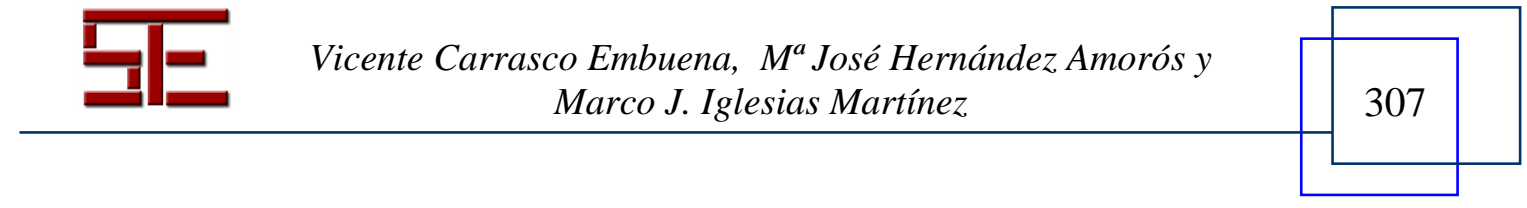




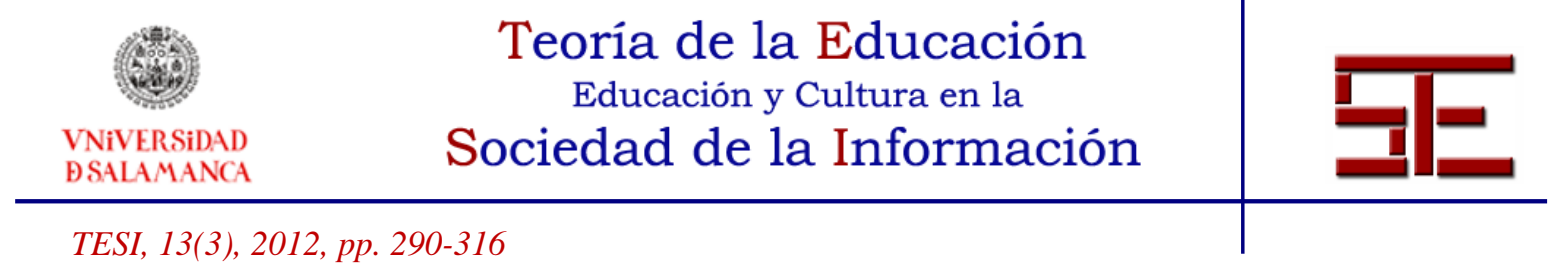

Al igual que el concepto de identidad, la noción de perfil docente es un conglomerado de aspectos diversos de naturaleza psicológica, social y cultural, que exigen una consideración amplia del término (Sayago, Chacón y Rojas, 2008). Con esta investigación hemos intentado identificar los perfiles que emergen de las concepciones y expectativas que expresan los estudiantes de Magisterio. Los resultados nos han permitido identificar cinco aspectos básicos que, a su juicio, deben sustentar el desempeño profesional, que incluyen competencias clave del perfil de los maestros y profesores y que son: a) poseer una personalidad crítica, sensible, proactiva y comprometida; b) disponer de formación y recursos pedagógicos amplios; c) poseer habilidades comunicativas y sociales; d) tener capacidad para dirigir su tarea hacia la formación integral de los estudiantes; y e) evidenciar talento para desempeñar sus tareas con altos niveles de calidad, influyendo en el desarrollo académico y personal de sus alumnos/as.

En el primer apartado de este trabajo aludíamos a que la profesión docente tiene un marcado carácter vocacional porque exige compromiso, actitud positiva $\mathrm{y}$ responsabilidad en el ejercicio profesional, que lleva aparejada la búsqueda de la innovación como exigencia para hacer de la enseñanza un diálogo permanente entre las necesidades de los estudiantes y las exigencias de la sociedad que los proyecta y de la que son parte fundamental (González y Génova, 2008). Los resultados de nuestro estudio alertan de la necesidad de que en los centros de formación del profesorado se trabaje no sólo la vertiente académica y el desarrollo de la aptitud pedagógica, sino aquellas otras competencias que hacen de maestros y profesores figuras con capacidad de influencia en sus estudiantes. Los nuevos planes de estudios de los Grados de Maestro se orientan a desarrollar competencia en los futuros profesionales, pero es necesario que esa competencia se asiente en la formación íntegra de los estudiantes. Es conveniente promover una visión amplia de la educación de los profesores (Korthagen, 2004) que atienda la competencia global referida porque sigue plenamente vigente aquella reiterada idea de Darling-Hammond (1996, 1997, 1998a, 1998b) de que la educación y el desarrollo profesional de los profesores son una de las variables que mayor influencia tienen en la calidad de la educación.

Concluimos este trabajo conscientes de que tenemos algunas tareas pendientes. Las preconcepciones subyacen a todo conocimiento, como lentes a través de las que se filtran las nuevas ideas, orientando la actuación y convirtiéndose en posibilidad o

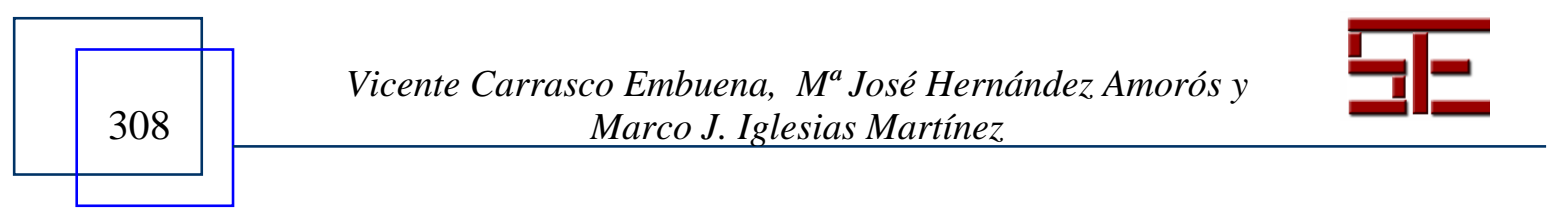




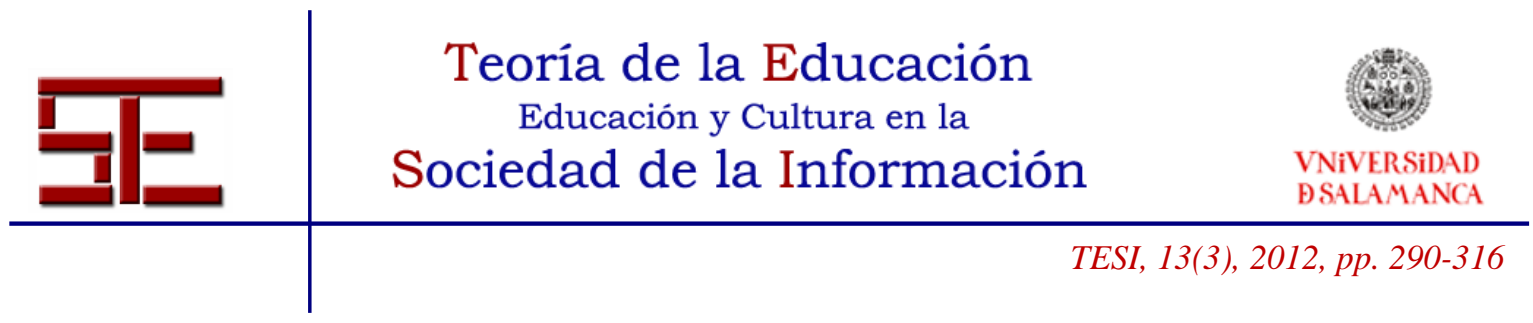

limitación para la construcción del conocimiento (Bretones, 2003). Por ello, debemos intentar dilucidar los dilemas sobre el origen de la vocación docente, estudiando las preconcepciones que tienen los estudiantes de los Grados de Maestro cuando inician sus estudios para, posteriormente, contrastarlas con las ideas sobre la profesión y los perfiles competenciales que van forjando mediante la formación específica. Ese será el propósito de alguna de nuestras tareas futuras.

\section{REFERENCIAS}

ANECA (2005). Libro Blanco. Título de Grado de Magisterio. Madrid: Omán impresores.

Avent, J. E. (1931). The Excellent Teacher. Tennessee: Joss E. Avent.

Bain, K. (2005). Lo que hacen los mejores profesores universitarios. Valencia: Publicaciones de la Universitat de València.

Bar, G. (1999). Perfil y competencias del docente en el contexto institucional educativo. Consultado el 26 de marzo de 2003 en: http://educaion.jalisco.gov.mx/consulta/educar/05.html

Barr, A. S, Eustice, D. E., \& Noe, E. J. (1995). The Measurement and Prediction of Teacher Efficiency. Review of Educational Research, 25 (3), 261-269.

Becker, B. J., Kennedy, M. M., \& Hundersmark, S. (2003). Communities of scholars, research and debates about teacher quality. Paper presented at the annual meeting of the American Educational Research Association. Chicago.

Beijaard, D., Meijer, P. \& Verloop, N. (2004). Reconsidering research on teachers' professional identity. Teaching and Teacher Education, 20, 107-128.

Borich, G. D. (1986). Paradigms of Teacher Effectiveness Research: their relationship to the concept of effective teacher. Education and Urban Society, 18 (2), 143-167.

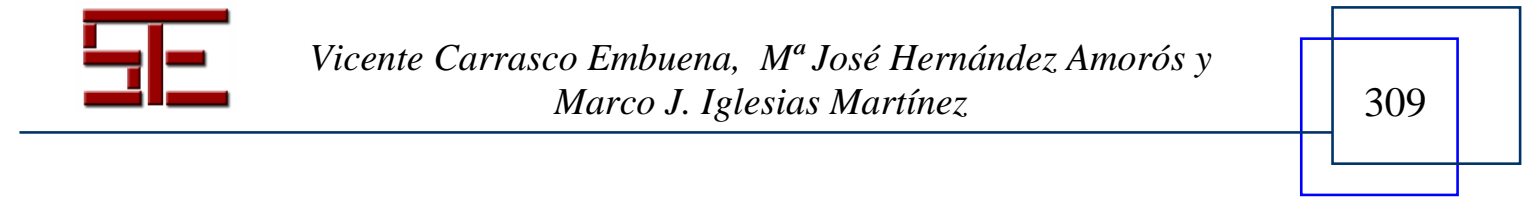




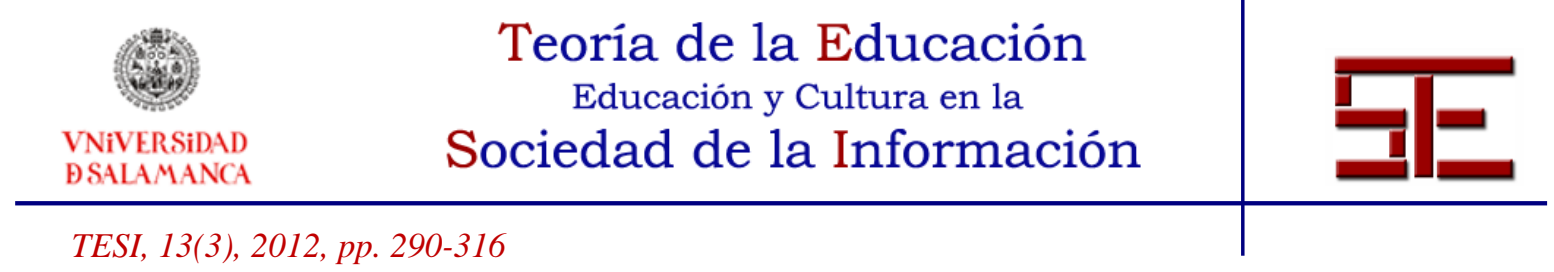

Braslavsky, C. (1999). Bases, orientaciones y criterios para el diseño de programas de formación de profesores. Consultado el 18 de octubre de 2003 en: http://oei.gov.co.htlm

Bretones, A. (2003). Las preconcepciones del estudiante de profesorado: de la construcción y transmisión del conocimiento a la participación en el aula. Educar, 32, 25-54.

Bullough, R.V. (1997). Practicing theory and theorizing practice. In J. Loughran \& T. Rusell (Eds.), Purpose, passion and pedagogy in teacher education (pp. 13-31). London: Falmer Press.

Cano, E. (2005). Cómo mejorar las competencias de los docentes. Guía para la autoevaluación y el desarrollo de las competencias del profesorado. Barcelona: Graó.

Castaño, P. (2009). Profesores que dejan huella. Servicio de publicaciones de la Universidad de Extremadura.

Coldron, J. \& Smith, R. (1999). Active location in teachers' construction of their professional identities. Journal of Curriculum Studies, 31 (6), 711-726.

Conelly, F. M. \& Clandinin, D.J. (1999). Shaping a professional identity: Stories of education practice. London, ON: Althouse Press.

Cooper, K. \& Olson, M. R. (1996). The multiple "I's" of teacher identity. In M. Kompf, W.R. Bond, D. Dworet \& R. T. Boak (Eds.), Changing research and practice: Teachers' professionalism, identities and knowledge (pp.78-89). London/Washington, DC: The Falmer Press.

Coto, M. \& Dirckinck-Holmfeld, L. (2007). Diseño para un aprendizaje significativo. Revista Electrónica de Teoría de la Educación. Educación y Cultura en la Sociedad de la Información, 8 (3), 135-148.

Cruiskhank, D. \& Haefele, D. (2001). Good Teachers, Plural. Educational Leadership, 58(5), 26-30.

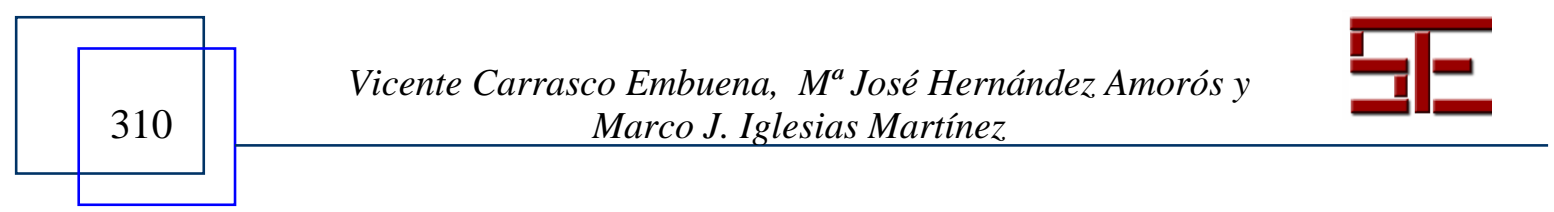




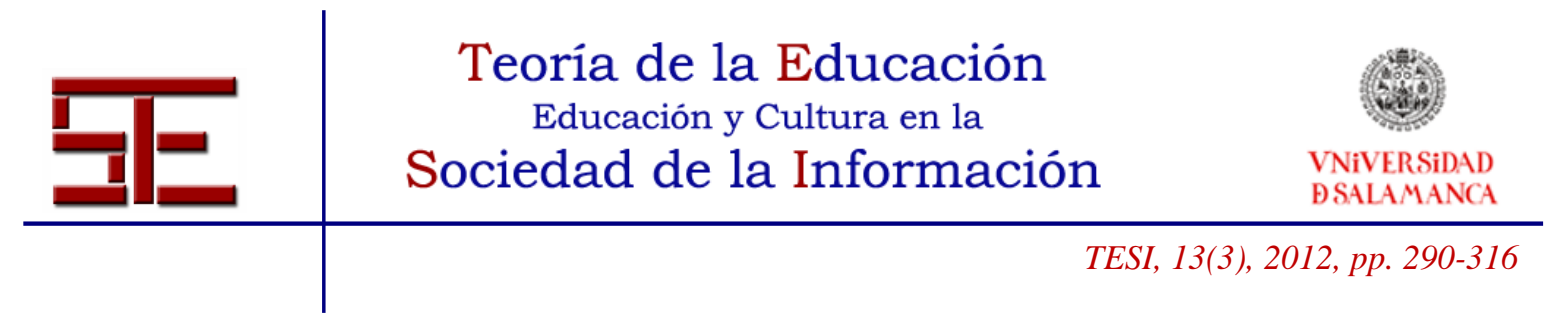

Cuadrado, I. \& Fernández, A. (2008). Nuevas competencias del profesor en el EEES: Una experiencia de innovación docente. Revista Electrónica de Teoría de la Educación. Educación y Cultura en la Sociedad de la Información, 9 (1), pp.200-211.

Darling-Hammond, L. (1996). The right to learn and the advancement of teaching: Research, policy, and practice for democratic education. Educational Researcher, 6, 517.

- (1997). The right to learn. A blueprint for creating schools that work. San Francisco: Jossey-Bass Publishers.

- (1998a). Policy and change: Gettong beyond bureaucracy. En A. Hargreaves, A. Lieberman, M. Fullan y D. Hopkins, International handbook of educational change, (642-667). Dordrech: Kluwer Academic Publishers.

- (1998b). Teachers and teaching: Testing policy hypotheses from a National commission Report. Educational Researcher, 27 (1), 5-15.

Day, C. (2006). Pasión por enseñar. La identidad personal y profesional del docente y sus valores. Madrid: Narcea.

Delors, J. (1996). La educación encierra un Tesoro. Madrid: UNESCO-Santillana.

Epstein, J. L. (2001). School, family, and community partnerships: Preparing educators and improving schools. Boulder, CO: Westview Press.

Finkel, D. (2008). Dar clase con la boca cerrada. Publicaciones de la Universitat de València.

Fullan M. \& Hargreaves A. (1996). La escuela que queremos. Los objetivos por los cuales vale la pena luchar. Buenos Aires: Amorrortu.

García Gómez, M. S. (1999). La formación permanente del profesorado y su incidencia en las aulas. Estudio de un caso. Revista de Investigación Educativa, 17 (1), 149-166.

González, M. R. \& Génova, G. (2008). Innovación docente a la luz de Bolonia: Trabajo en equipo y revisiones cruzadas para convertir al alumno en protagonista de su proceso

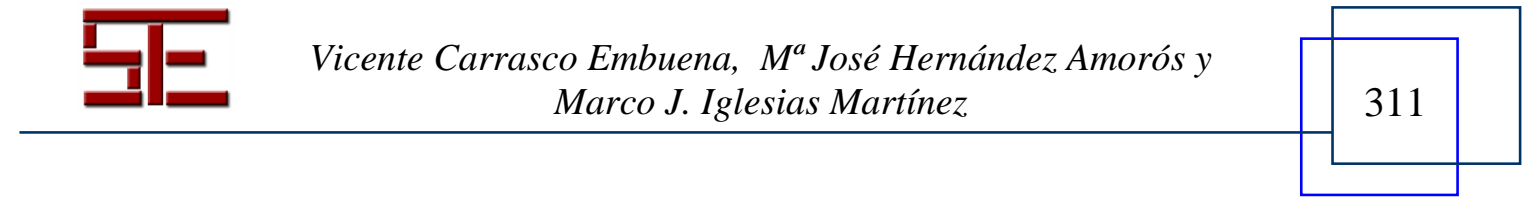




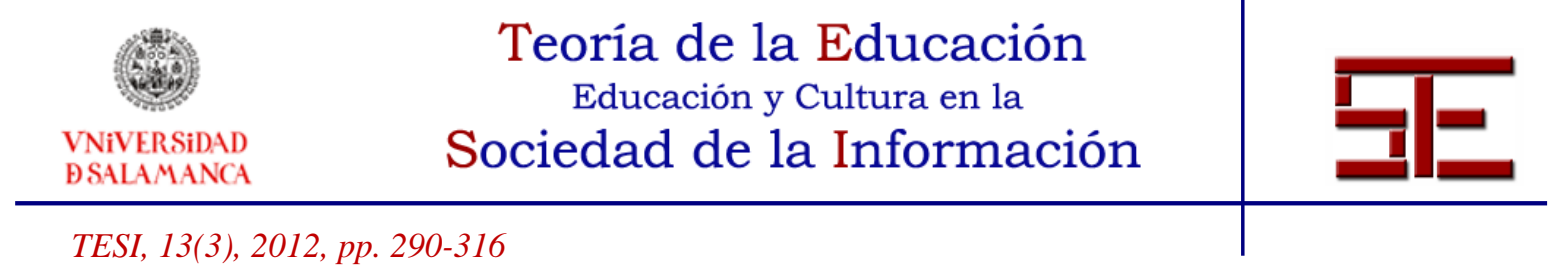

de aprendizaje. Revista Electrónica Teoría de la Educación. Educación y Cultura en la Sociedad de la Información, 9 (1), 126-141.

Harré, R. (1983). Personal Being. A Theory for Individual Psychology. (Ways of Being). Oxford: Blackwell.

Huber, G. L. (2006). AQUAD 6. Manual del programa para analizar datos cualitativos. Ed. Verlag Ingeborg Huber. Recuperado el 12/07/2010 en http: //www.aquad.de/spa/manual. Pdf.

Imbernón, F. (2002). La investigación educativa como herramienta de formación del profesorado, reflexión y experiencias de investigación educativa. Barcelona: Graó.

Knowles, G. J. (1992). Models for understanding pre-service and beginning teachers' biographies: Illustrations from case studies. En I. F. Goodson (Ed.), Studying teachers' lives (pp. 99-152). London: Routledge.

Kompf, M., Bond, W.R., Dworet, D. \& Boak, R.T. (Eds.) (1996). Changing research and practice: Teachers' professionalism, identities and knowledge. London, Washington, DC: Falmer Press.

Korthagen, F. (2004). In search of the essence of a good teacher: towards a more holistic approach in teacher education. Teaching and Teacher Education, 20, 77-97.

Mc Court, F. (2008). El profesor. Madrid: Maeva Ediciones.

Morin, E. (2000). Les sept savoirs nécessaires à l'éducation du futur. Paris: Seuil.

Noddings, N. (2003). Caring: A feminine approach to ethics and moral education. Berkeley: University of California Press.

Peart, N. A. \& Campbell, F. A. (1999). At-Risk Student's Perceptions of Teacher Effectiveness. Journal for a Just and Caring Education, 5, 269-284.

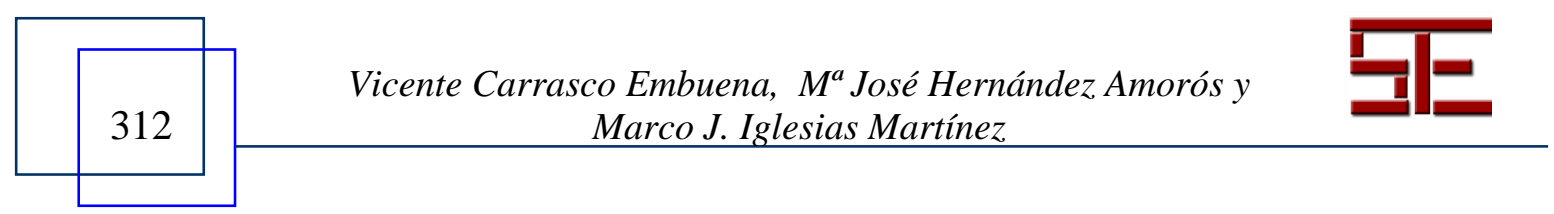




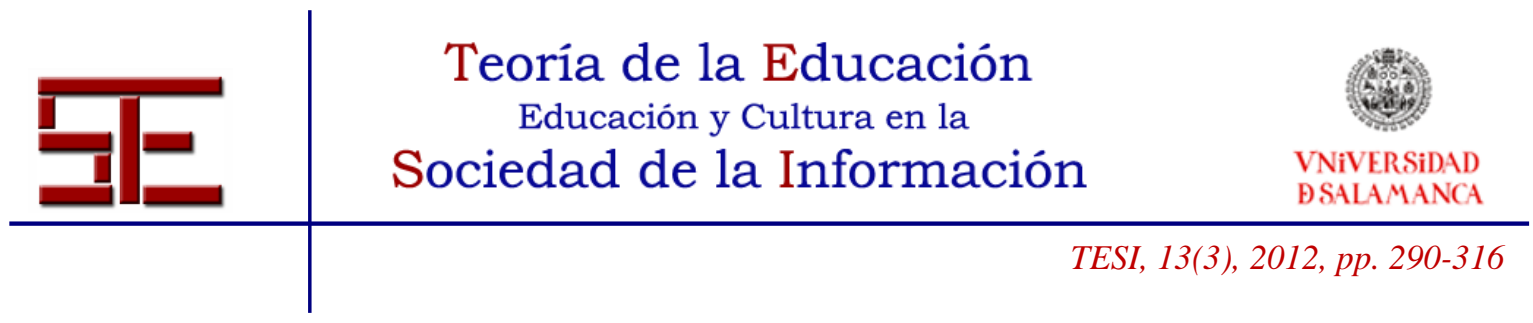

Pennac, D. (2009). Mal de escuela. Barcelona: DeBolsillo.

Perrenoud, P. (2004). Diez nuevas competencias para enseñar. Barcelona: Graó.

Reid, J. (1999). Improving Teaching in Higher Education: student and teacher perspective. Educational Studies, 25 (3), 269-282.

Sánchez, A. y Boix, L. (2008). La construcción de la identidad y profesionalización de los docentes noveles de la ESO, a través de un estudio experimental. Profesorado. Revista de currículum y formación del profesorado, 12 (3).

Savater, F. (1997). El valor de educar. Barcelona: Ariel.

Sayago, Z., Chacón, M. y Rojas, M. (2008). Investigación arbitraria. Construcción de la identidad profesional docente en estudiantes universitarios. EDUCERE. Investigación arbitraria, $\quad 12 \quad$ (42), pp. 551-561. Disponible en: http://www.saber.ula.ve/bitstream/123456789/26312/1/articulo15.pdf.

Silverman, D. (2000). Analysing talk and text. En N. K. Denzin e Y. Lincoln, Handbook of qualitative research. London: Sage Publications, Inc.

Stronge, J. H. (2007). Qualities of effective teachers. USA: ASCD.

Tickle, L. (2000). Teacher induction: The way ahead. Buckingham, Philadelphia: Open University Press.

Trueba, B. (1997). Enfoques pedagógicos y proceso evolutivo docente en educación infantil. Aula de Innovación Educativa, 62, 43-48.

Volkmann, M. J. \& Anderson, M. A. (1998). Creating professional identity: Dilemmas and metaphors of a first-year chemistry teacher. Science Education, 82 (3), 293-310.

Zabalza, M. A. (2003). Competencias docentes del profesorado universitario. Calidad y

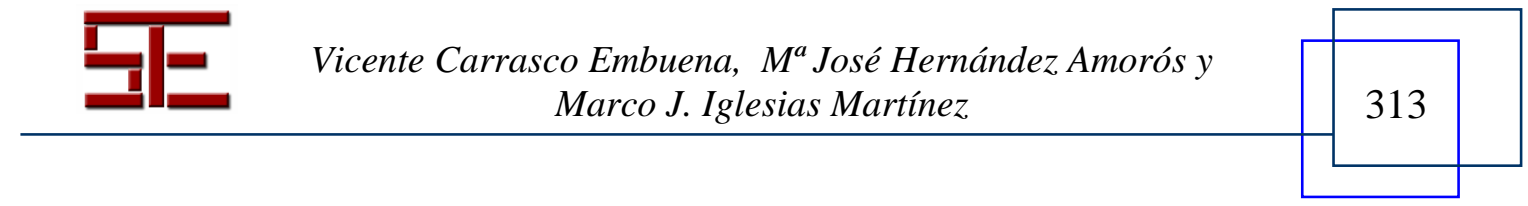


desarrollo profesional. Madrid: Narcea.

- (2009). Ser profesor universitario hoy. La cuestión universitaria, 5,69-81.

\section{Anexo 1. Categorías y códigos}

\begin{tabular}{|c|c|}
\hline Categorías & Códigos \\
\hline \multirow{7}{*}{ Cualidades personales } & Buena presencia \\
\hline & Buena actitud \\
\hline & Transmisión gusto asignatura \\
\hline & Paciencia \\
\hline & Humildad \\
\hline & Recuerdo de exalumnos/as \\
\hline & Vocación por enseñar \\
\hline \multirow{7}{*}{ Aptitud pedagógica } & Recursos educativos \\
\hline & Conocimientos del maestro \\
\hline & Clases amenas \\
\hline & Contenidos interesantes \\
\hline & Experiencias del maestro \\
\hline & Promoción aprendizajes significativos \\
\hline & Estrategias para evaluar \\
\hline \multirow{10}{*}{$\begin{array}{l}\text { Calidad de los procesos de } \\
\text { interacción }\end{array}$} & Preocupación alumnos/as \\
\hline & Ayuda alumnos/as \\
\hline & Apoyo emocional \\
\hline & Escucha alumnos/as \\
\hline & Protección dignidad \\
\hline & Potenciación cualidades \\
\hline & Atención a las características individuales \\
\hline & Valoración del esfuerzo \\
\hline & Trato con alumnos/as \\
\hline & Atención a padres \\
\hline \multirow[t]{2}{*}{ Formación } & Formación en valores \\
\hline & Formación personal \\
\hline \multirow[t]{4}{*}{ Repercusión de la actuación docente } & Influencia etapa vida \\
\hline & Influencia elección vocacional \\
\hline & Influencia en estudios \\
\hline & Transmisión gusto asignatura \\
\hline
\end{tabular}




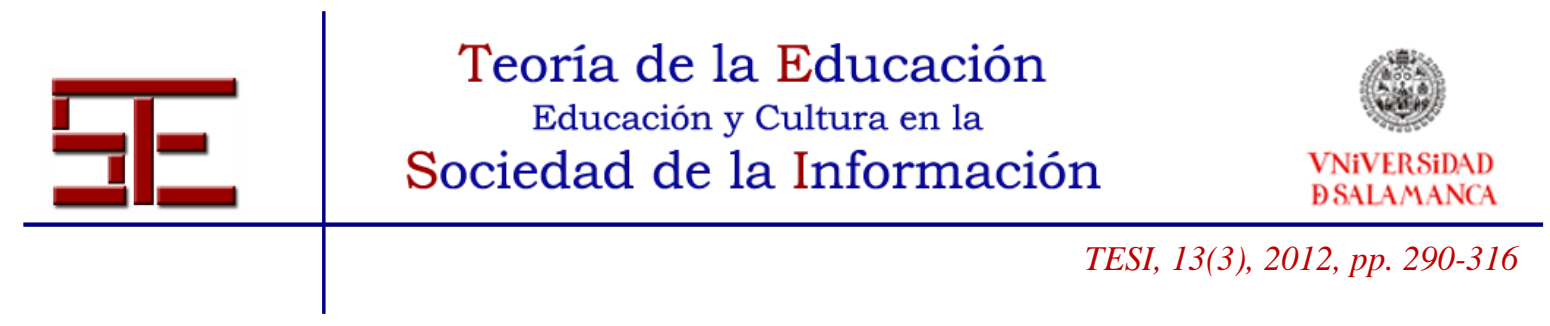

\section{Anexo 2. Relación entre competencias transversales y específicas del Libro Blanco (LB) y categorías emergentes en la investigación}

\begin{tabular}{|c|c|c|c|}
\hline 1 & 2 & CÓDIGOS & COMPETENCIAS ESPECÍFICAS \\
\hline \multirow{6}{*}{ 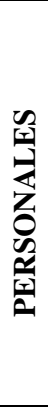 } & \multirow{6}{*}{ 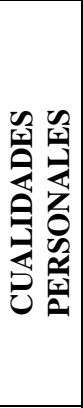 } & Buena presencia & \multirow{3}{*}{$\begin{array}{l}\text { Tener una imagen realista de sí mismo, actuar conforme a las propias } \\
\text { convicciones, asumir responsabilidades, tomar decisiones y relativizar las } \\
\text { posibles frustraciones. }\end{array}$} \\
\hline & & $\begin{array}{l}\text { Buena actitud } \\
\text { Transmisión gusto } \\
\text { asignatura }\end{array}$ & \\
\hline & & Paciencia & \\
\hline & & \multicolumn{2}{|c|}{ Humildad, recordar a ex alumnos/as (cualidades del maestro) } \\
\hline & & \multirow[b]{2}{*}{ Vocación por enseñar } & $\begin{array}{l}\text { Capacidad de asumir la necesidad de desarrollo profesional continuo, } \\
\text { mediante la autoevaluación de la propia práctica. }\end{array}$ \\
\hline & & & $\begin{array}{l}\text { Participar en proyectos de investigación relacionados con la enseñanza y } \\
\text { el aprendizaje, introduciendo propuestas de innovación encaminadas a la } \\
\text { mejora de la calidad educativa. }\end{array}$ \\
\hline \multirow{10}{*}{ 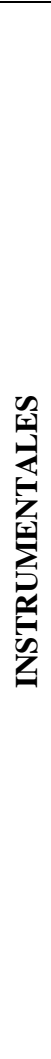 } & \multirow{10}{*}{ 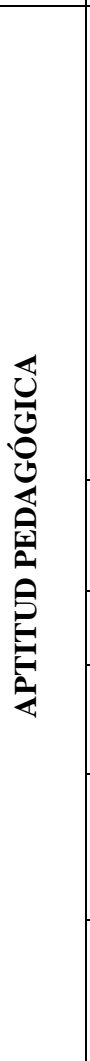 } & \multirow{4}{*}{ Recursos educativos } & $\begin{array}{l}\text { Capacidad para organizar la enseñanza, en el marco de los paradigmas } \\
\text { epistemológicos de las áreas, utilizando de forma integrada los saberes } \\
\text { disciplinares, transversales y multidisciplinares adecuados al respectivo } \\
\text { nivel educativo. }\end{array}$ \\
\hline & & & $\begin{array}{l}\text { Capacidad para preparar, seleccionar o construir materiales didácticos y } \\
\text { utilizarlos en los marcos específicos de las distintas disciplinas. }\end{array}$ \\
\hline & & & $\begin{array}{l}\text { Capacidad para comprender la complejidad de los procesos educativos en } \\
\text { general y de los procesos de enseñanza-aprendizaje en particular (fines y } \\
\text { funciones de la educación y del sistema educativo, teorías del desarrollo y } \\
\text { del aprendizaje, el entorno cultural y social, etc.). }\end{array}$ \\
\hline & & & $\begin{array}{l}\text { Capacidad para utilizar e incorporar adecuadamente en las actividades de } \\
\text { enseñanza-aprendizaje las tecnologías de la información y la } \\
\text { comunicación. }\end{array}$ \\
\hline & & \multirow[b]{2}{*}{$\begin{array}{l}\text { Conocimientos del } \\
\text { maestro }\end{array}$} & Sólida formación científico-cultural y tecnológica. \\
\hline & & & $\begin{array}{l}\text { Conocimiento de los contenidos que hay que enseñar, comprendiendo su } \\
\text { singularidad epistemológica y la especificidad de su didáctica. }\end{array}$ \\
\hline & & $\begin{array}{l}\text { Clases amenas } \\
\text { Contenidos interesantes }\end{array}$ & $\begin{array}{l}\text { Diseño y desarrollo de proyectos educativos y unidades de programación } \\
\text { que permitan adaptar el currículo al contexto sociocultural. }\end{array}$ \\
\hline & & Experiencias del maestro & $\begin{array}{l}\text { Capacidad para analizar y cuestionar las concepciones de la educación } \\
\text { emanadas de la investigación así como las propuestas curriculares de la } \\
\text { Administración Educativa. }\end{array}$ \\
\hline & & $\begin{array}{l}\text { Promoción aprendizajes } \\
\text { significativos }\end{array}$ & $\begin{array}{l}\text { Capacidad para promover el aprendizaje autónomo de los alumnos a la } \\
\text { luz de los objetivos y contenidos propios del correspondiente nivel } \\
\text { educativo, desarrollando estrategias que eviten la exclusión y la } \\
\text { discriminación. }\end{array}$ \\
\hline & & Estrategias para evaluar & $\begin{array}{l}\text { Capacidad para utilizar la evaluación, en su función propiamente } \\
\text { pedagógica y no meramente acreditativa, como complemento regulador y } \\
\text { promotor de la mejora de la enseñanza, del aprendizaje y de su propia } \\
\text { formación. }\end{array}$ \\
\hline
\end{tabular}

Vicente Carrasco Embuena, $M^{a}$ José Hernández Amorós y Marco J. Iglesias Martínez 


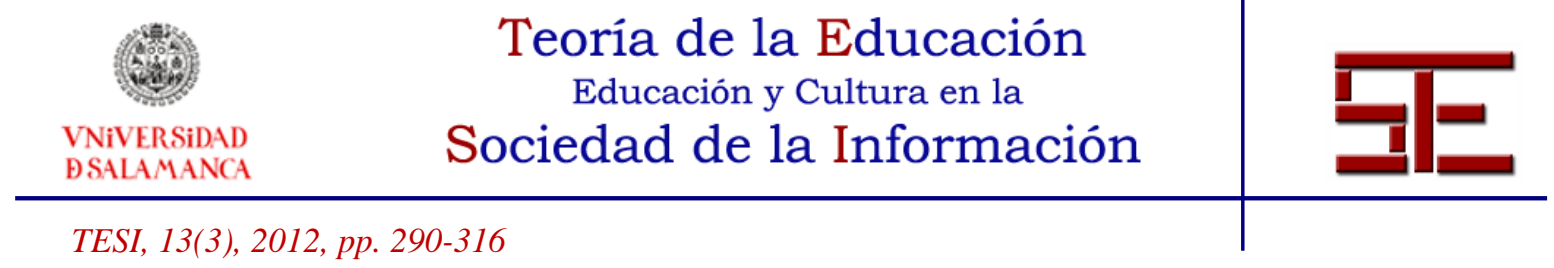

\begin{tabular}{|c|c|c|c|}
\hline \multirow{12}{*}{ 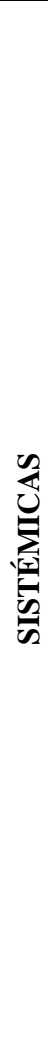 } & \multirow{12}{*}{ 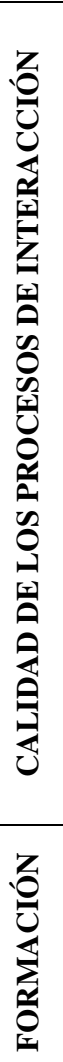 } & $\begin{array}{l}\text { Preocupación por los } \\
\text { alumnos/as }\end{array}$ & $\begin{array}{l}\text { Capacidad para dinamizar con el alumnado la construcción participada de } \\
\text { reglas de convivencia democrática, y afrontar y resolver de forma } \\
\text { colaborativa situaciones problemáticas y conflictos interpersonales de } \\
\text { naturaleza diversa. }\end{array}$ \\
\hline & & Ayuda alumnos & $\begin{array}{l}\text { Capacidad para desempeñar la función tutorial, orientando a alumnos y } \\
\text { padres y coordinando la acción educativa referida a un grupo de alumnos. }\end{array}$ \\
\hline & & Apoyo emocional & $\begin{array}{l}\text { Respeto a las diferencias culturales y personales de los alumnos y demás } \\
\text { miembros de la comunidad educativa. }\end{array}$ \\
\hline & & Escucha alumnos/as & $\begin{array}{l}\text { Capacidad de relación y de comunicación, así como de equilibrio } \\
\text { emocional en las variadas circunstancias de la actividad profesional. }\end{array}$ \\
\hline & & Protección dignidad & $\begin{array}{l}\text { Capacidad para promover la calidad de los contextos (aula y centro) en } \\
\text { los que se desarrolla el proceso educativo, de modo que se garantice el } \\
\text { bienestar de los alumnos. }\end{array}$ \\
\hline & & Potenciación cualidades & \\
\hline & & $\begin{array}{l}\text { Atención a las } \\
\text { características } \\
\text { individuales }\end{array}$ & $\begin{array}{l}\text { Capacidad para realizar actividades educativas de apoyo en el marco de } \\
\text { una educación inclusiva. }\end{array}$ \\
\hline & & Valoración del esfuerzo & \\
\hline & & Trato con alumnos & $\begin{array}{l}\text { Capacidad de relación y comunicación, así como de equilibrio emocional } \\
\text { en las variadas circunstancias de la actividad profesional. }\end{array}$ \\
\hline & & Atención a padres & $\begin{array}{l}\text { Capacidad para colaborar con los distintos sectores de la comunidad } \\
\text { educativa y del entorno. }\end{array}$ \\
\hline & & Formación en valores & $\begin{array}{l}\text { Asumir una dimensión ética del maestro potenciando en el alumnado una } \\
\text { actitud de ciudadanía crítica y responsable. }\end{array}$ \\
\hline & & Formación personal & $\begin{array}{l}\text { Compromiso de potenciar el rendimiento académico de los alumnos y su } \\
\text { progreso escolar en el marco de una educación integral. }\end{array}$ \\
\hline & & REPEI & USIÓN DE LA ACTUACIÓN DOCENTE \\
\hline & & pa vida & \\
\hline & enci & ección vocacional & \\
\hline Inf & & estudios & \\
\hline & & gusto asignatura & \\
\hline
\end{tabular}

Para citar el presente artículo puede utilizar la siguiente referencia:

Carrasco Embuena, V., Hernández Amorós, M. J. y Iglesias Martínez, M. J. (2012). Aportaciones de los maestros en formación a la construcción del perfil del docente competente desde la reflexión en el aula. Revista Teoría de la Educación: Educación y Cultura en la Sociedad de la Información. 13(3), 290-316 [Fecha de consulta: $\mathrm{dd} / \mathrm{mm} / \mathrm{aaaa}]$.

http://campus.usal.es/ revistas_trabajo/index.php/revistatesi/article/view/9142/9375

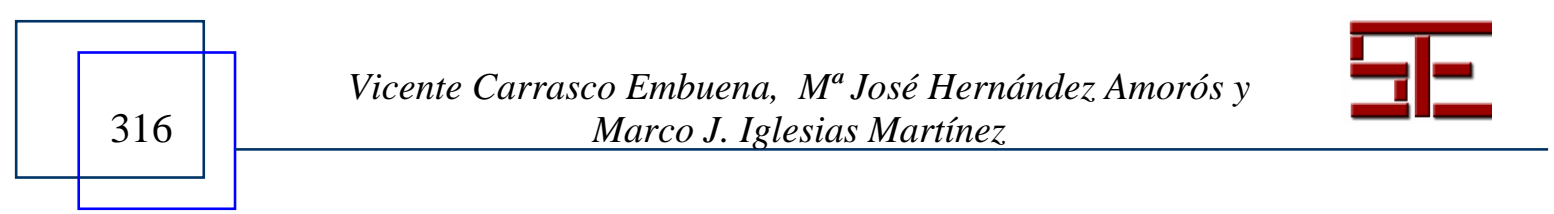

